\title{
Una mirada al antiimperialismo latinoamericano desde la invasión norteamericana en Nicaragua y la fundación de la Liga Anti-imperialista de San Salvador (1926-1927)
}

Roberto Deras

Universidad Centroamericana "José Simeón Cañas"

"La permanencia de las tropas yanquis en Nicaragua no sólo atenta contra la soberanía e independencia de ese país, sino de todas las otras cuatro repúblicas. Lanzar a los marinos, es conquistar la emancipación de los trabajadores centroamericanos. Una unión estrecha de los antimperialistas centroamericanos, una unión económica y política, la soñada UNIÓN DE MORAZÁN, debe ser la tarea inmediata...

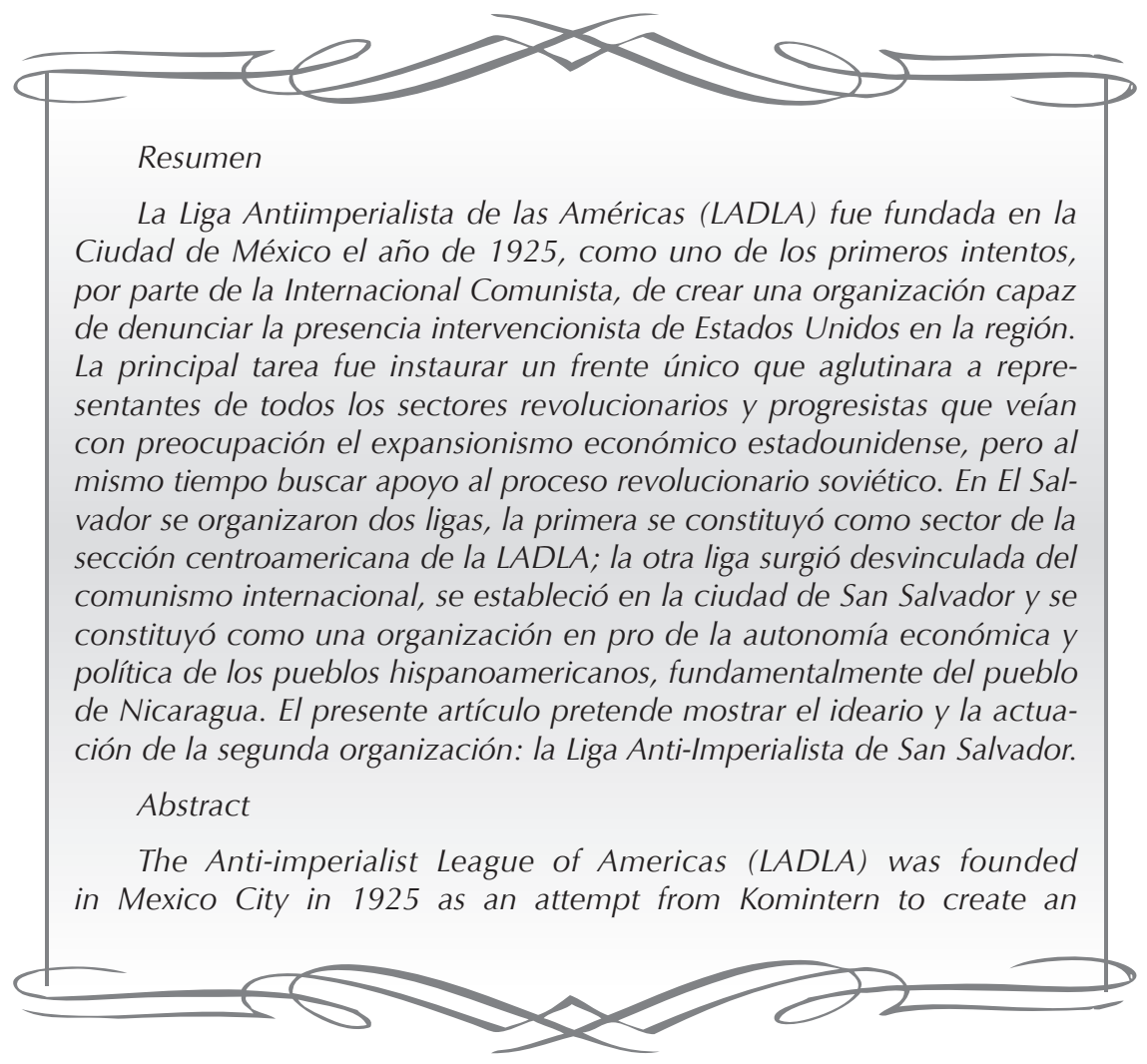




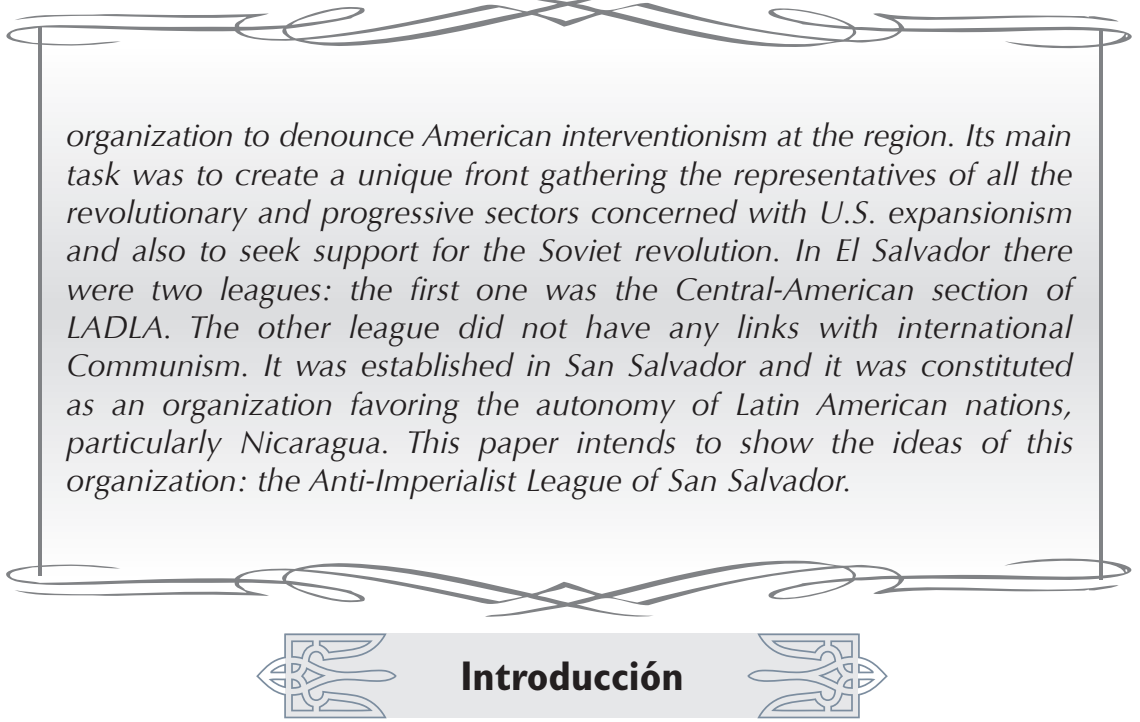

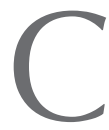

iertamente, el movimiento antiimperialista latinoamericano tuvo su apogeo hacía finales de los años veinte. Empero, para comprender todo el entramado y su membresía es necesario conocer el entorno teórico, político y social en el cual se desenvolvió. Evidentemente la situación en Nicaragua fue un detonante para la cohesión de diversos actores y asociaciones que buscaban enfrentarse a la política intervencionista e imperial de Estados Unidos. De igual manera, otras intromisiones económicas o políticas por parte del país norteamericano en el subcontinente contribuyeron al crecimiento del sentimiento solidario y antiimperialista de la región.

$Y$ es que a partir de los primeros años del siglo XX la lógica im- perial de las potencias occidentales cambió con la participación estadounidense. En concreto, la política exterior de dichas naciones pasó de ser colonialista a otros mecanismos de intervención y dominación: "Los europeos utilizan una intervención directa bajo el mecanismo de convertir a los territorios ocupados al estatus de colonia; en cambio, los norteamericanos deben utilizar los mecanismos de la intervención o domino indirecto" ${ }^{2}$. Sin lugar a duda, el imperialismo norteamericano, tal como sugiere el historiador francés Jean Baptista Duroselle, se sustenta en bases estratégicas y económicas ${ }^{3}$, es decir, en la protección política y económica que conduce en muchos casos a una presión comercial y financiera que implicaba la transferencia de propiedades nacionales a banqueros norteameri- 
canos. En definitiva, Centroamérica y el Caribe se vieron arrastradas por esa política exterior norteamericana.

En ese sentido, el caso de Nicaragua constituyó una inquietud especial para Estados Unidos durante las primeras décadas del siglo pasado. Una de las principales causas fue su ubicación y posibilidades geográficas; por tanto, una preocupación estratégica y económica era la construcción de otro canal interoceánico -adicional al panameño- en el istmo por alguna potencia rival como Japón o Gran Bretaña. Indiscutiblemente, una posible acción de esa magnitud generaba una verdadera amenaza a los intereses económicos y políticos norteamericanos. Así, la primera invasión estadounidense en Nicaragua durante el siglo XX ocurrió en octubre de 1912 y duró hasta agosto de 1925; sin temor a equivocación, la más larga ocupación en América Latina.

Un año previo a la retirada norteamericana, se celebraron elecciones en el país de los lagos. Carlos Solórzano, conservador, fue elegido presidente, y el doctor Juan Bautista Sacasa, liberal, vicepresidente. En 1925, luego de la salida de la guardia de Infantería Marina, Adolfo Díaz y Emiliano Chamorro depusieron a Solórzano y le obligaron, junto a Bautista Sacasa, a abandonar el país. No obstante, los Estados Unidos se opusieron a Chamorro y decretaron el embargo de armas y municiones para Nicaragua. El congreso nicaragüense, pese a todo el malestar que ocasionaría en el país y en la región, eligió a Díaz como presidente. El gobierno norteamericano lo reconoció inmediatamente y, a la vez, levantó el embargo de armas. Adolfo Díaz solicitó apoyo al Presidente Calvin Coolidge (Republicano), para acabar con la resistencia liberal encabezada por Sacasa y el general José María Moncada. Cooligde hizo volver la marina a Nicaragua a principios de 1927. En otras palabras, el desembarco no era más que una nueva ocupación militar, la cual duraría hasta 1933.

En El Salvador, uno de los sectores que reaccionó con mayor ímpetu fue el de los intelectuales y periodistas. Su evolución, y postura ideológica, respecto a los abusos de poder cometidos en Nicaragua pasó del mero cuestionamiento a la acción política; logrando un antiimperialismo beligerante que llegó a la constitución de organizaciones abiertamente antinorteamericanas. Tal fue el caso de la Liga Antiimperialista de San Salvador.

\section{Corrientes y debate sobre el antimperialismo yanqui en América Latina entre 1920 - 1930}

En este primer apartado se expondrán las principales ideas que sustentaron el debate teórico y político utilizado para encarar 
el expansionismo estadounidense en América Latina. Para una mejor aproximación a todos esos argumentos antiimperialistas rastreados en la segunda y tercera década del siglo pasado, se han aglutinado dichas ideas y concepciones en cuatro grandes corrientes: arielista, cominternista o socialista, nacionalista revolucionaria y unionista.

\subsection{José E. Rodo y el arielismo: reacción al modelo cultural norteamericano y búsqueda de identidad en lo latinoamericano}

A inicios del siglo XX la búsqueda de la identidad latinoamericana se incrementó. Muchos intelectuales, escritores y periodistas de la época se sentían amenazados ante el positivismo que había caracterizado la última mitad del siglo XIX. Como respuesta surgieron una serie de pensadores con una clara apuesta antipositivista: Antonio Caso y José Vasconcelos en México; Manuel Ugarte y José Ingenieros en
Argentina; Manuel González Prada, en Perú y José Enrique Rodó en Uruguay.

Precisamente una de las nuevas corrientes que más impacto generó fue la que fundó Rodó: el arielismo. Su novela, Ariel, publicada en 1900, fue considerada como un Ilamado a la reflexión a la juventud de América Latina para rescatar su propia identidad. De ahí entonces que el arielismo haya sido vinculado con el antimperialismo. Ariel sintetiza los valores del espíritu frente a un Calibán del norte (emblema de la civilización materialista) que con sus prácticas utilitaristas había olvidado la formación integral del ser humano. En otras palabras, Ariel sirvió a los intelectuales latinoamericanos, preocupados por la creciente influencia y presencia norteamericana en la región, para definir, diferenciar y defender la Patria Grande. En palabras de Jussi Pakkasvirta, Rodó logró generar un sentido de identidad en el subcontinente:

\begin{abstract}
El idealismo arielista elevó esta utopía continental a un nivel ético y cultural; las repúblicas hispanoparlantes no formarían en el futuro sólo la nación más grande del mundo sino también la nación más civilizada y moralista. Sólo habría que unirse y rechazar el materialismo y el positivismo anglosajones, ganarlos con las virtudes de la espiritualidad latina ${ }^{4}$.
\end{abstract}

Es más, como señala Carlos Beorlegui, Rodó, a través del Ariel, dibuja de manera ejemplar el cam- bio de paradigma del pensamiento latinoamericano que implicó el tránsito de siglo: 
El rechazo de la cultura española, a la que se le achacaba el retraso americano, y la admiración hacia los Estado Unidos, da un giro importante hacia un rechazo de lo yanqui (los temores imperialistas quedan justificados) y un intento de revalorización de lo hispano ${ }^{5}$.

Asimismo, en su obra Rodó realiza un llamado de atención sobre el vicio de ver a las grandes potencias imperiales como paradigmas de salvación frente al atraso y como camino de progreso. Su propuesta por alcanzar una nueva cultura latinoamericana no se basó únicamente en obtener un desarroIlo económico, tecnológico o científico, sino en la creación de seres humanos. Para Rodó, con ello se lograría un nuevo continente, una nueva América.

En conclusión, el arielismo significó un nacionalismo-continentalismo espiritual e hispanista. Por otro lado, el peso intelectual de la citada corriente descansaba en su antimperialismo (antiestadounidense). De ahí entonces que la repercusión que tuvo propagó una de las corrientes antimperialistas más fecundas. Una muestra de esa afirmación es el número de publicaciones (revistas) que emergieron entre las décadas de 1920 y 1930, las cuales asumían el nombre de la obra máxima de Rodó: Ariel ${ }^{6}$. En otros términos, no cabe la menor duda que el pensamiento arielista se ocupó de reaccionar contra la tendencia a imitar el modelo norteamericano y como búsqueda de la identidad en lo propio. Dicha corriente representa la unidad continental por medio de vínculos de tradición, raza, idioma e instituciones; pero también es una idea más elevada que la de patria natal. Es la idea de América concebida como unidad grande e imperecedera.

\subsection{Propuestas de corte marxista: el cominternismo (acuerdos del V Congreso del Comintern, 1924) y el socialismo de José Carlos Mariátegui}

Entre otra de las corrientes antiimperialistas que circularon a lo largo del continente americano se encuentra la cominternista, es decir, la corriente suscrita a la Internacional Comunista (IC), cuya tradición se fundamentó en el marxismoleninismo que apadrinaba la Unión Soviética. Se trató de un ideario que se propagó a nivel mundial y, a su vez, se alimentó de la premisa rusa de hacer la revolución socialista en todo el planeta. En esa línea, se debe establecer que desde los primeros congresos de la Internacional Comunista era aceptado que dicha instancia debía ser dirigida, tanto institucional como teóricamente, por la experiencia rusa. En este sentido, a parte de Lenin, otro de los teóricos comunistas con mayor in- 
fluencia en este contexto fue Zinoviev, quien ya en 1920 planteaba la importancia y necesariedad de los "soviets" en la etapa de transición del capitalismo al comunismo total.

Bajo esos supuestos, el cominternismo planteaba que después de Rusia el proceso revolucionario debía tener su continuación en todo el mundo, iniciando su devenir en las potencias europeas, siendo Alemania la puerta de entrada. No obstante, esta inicial seguridad acerca de las tesis sobre el proceso histórico mundial fue poco a poco cediendo, pues en los países dependientes acaecían revoluciones con características ajenas a la dinámica europea.

Precisamente desde el V Congreso de la IC, Ilevado a cabo en Moscú a mediados de 1924, se abrió el debate sobre el papel de las regiones coloniales y el mundo periférico. En ese sentido, las representaciones de los países dependientes dejaron sentado que muchos sectores organizados en las colonias no buscaba la revolución mundial; más bien se encasillaban entre lo que se conoce como luchas nacionales de liberación, en las cuales no sólo estaba implicada la clase obrera sino otros actores: campesinos y cierto sector de la burguesía nacional. En otras palabras, dicha postura dejaba entredicho que la revolución mundial no debía iniciar necesariamente en Europa, ni que debía ser liderada exclusivamente por el proletariado ${ }^{7}$.
En tal sentido, uno de los principales aspectos a destacar de ese $\mathrm{V}$ Congreso fue la gestación del frente único antiimperialista. No obstante, dicha concepción de unificación a nivel mundial frente al capitalismo, y su manifestación imperialista, tampoco estaba exento de polémicas y discusiones. El planteamiento oficial del Comintern prescribía que la clase obrera debía acaparar o guiar el proceso revolucionario mundial $y$, por lo tanto, a todos los procesos revolucionarios en los distintos países. Por dicha razón, la presencia de Víctor Raúl Haya de la Torre en el $V$ congreso representó una potencial discusión al respecto. El planteamiento del peruano consistía en la instauración de alianzas estratégicas de distintos sectores para enfrentarse al imperio estadounidense. Sin embargo, para la jerarquía comunista el tema de las alianzas era visto como una mera herramienta coyuntural para lograr una situación revolucionaria. Dicha posición cominternista a la larga engendró situaciones complicadas para caudillos latinoamericanos como Augusto César Sandino, cuya lucha era eminentemente de liberación nacional y no socialista ${ }^{8}$.

En fin, para el año 1925, en una reunión del Comité Ejecutivo Ampliado de la Internacional Comunista, realizada del 25 marzo al 6 abril en Moscú, se replanteó la importancia de la cuestión colonial y latinoamericana en el proceso del proletariado mundial. Entre otros 
aspectos, se resolvió que el campesinado debía sumarse al proceso antiimperialista. En ese mismo marco se planteó que el Partido Comunista de los Estados Unidos debía liderar la lucha antiimperialista en comunicación y coordinación con los movimientos revolucionarios de los países dependientes de dicha potencia. Tal adhesión debía concretizarse a través de la recién fundada Liga Antiimperialista (LADLA), cuyo objetivo era apoyar $y$ aglutinar a todos los movimientos nacionalistas revolucionarios, campesinos y sindicales y "oponer una resistencia firme al imperialismo bajo cualesquiera formas en que se manifestara" ${ }^{\prime \prime}$.

Ahora bien, a partir de esa discusión, el "patio trasero" de la potencia americana empezó a figurar en los organismos de la Internacional. Por ejemplo, en ese mismo año, el representante cominternista mexicano, Bertrand Wolfe, informaba sobre el proceso de bolcheviquización del Partido Comunista de México $^{10}$. Una de las tareas que se resaltaban era la creación e impulso que había protagonizado la Liga Antiimperialista de las Américas (LADLA), misma que ya tenía sedes en muchos países de la región. También se informaba sobre la edición del periódico El Libertador ${ }^{11}$, órgano del frente único antiimperialista.

Ya para 1926 se otorgó una mayor importancia a la región. La estrategia era apoyar cualquier movimiento revolucionario no importando su carácter ideológico u objetivo inmediato, siempre y cuando el partido comunista implicado pudiera garantizar la conducción de dicho proceso para beneficiar los intereses de la clase trabajadora. Sin embargo, la presencia e influencia de la Internacional en América Latina, particularmente en el sector sindical era bastante débil. En esa dirección se decidió incrementar la presencia de dos instancias del Comintern: el Socorro Rojo Internacional (SRI) y la Liga Antiimperialista de las Américas (LADLA). El objetivo de ambos organismos era apoyar los procesos específicos de cada país: la LADLA, por ejemplo, apoyó la causa de Augusto César Sandino en Nicaragua; mientras que el SRI entabló relaciones con El Salvador, con el movimiento liderado por Agustín Farabundo Martí12.

En conclusión, previo al $\mathrm{VI}$ Congreso, América Latina seguía encasillada, junto a las situaciones coloniales de oriente, como piezas -secundarias- que "ayudaban" al proceso revolucionario mundial. Pese a esa visión peyorativa hacia el subcontinente y en específico a sectores como el campesinado, el antiimperialismo cominternista logró su cometido: se constituyó en una corriente de peso aplicándose como una entidad de denuncia y movilización frente a los abusos del expansionismo estadounidense. En el caso de Centroamérica, la adscripción a las ligas antiimperialistas 
se realizó a través de obreros, intelectuales y estudiantes; sin embargo, aparentemente carecieron de una sólida estructura organizativa. Probablemente sus limitantes responden a la existencia de otras opciones políticas antiimperialistas como el unionismo, el nacionalismo o el aprismo.

Otra de las vertientes del antiimperialismo de corte marxista es la que abanderó José Carlos Mariátegui. Su producción teórica antiimperialista se enmarca, principalmente, a partir de marzo de 1923, fecha en la que regresó del exilio al Perú. Es en ese marco donde centra su labor de investigación utilizando el método marxista e inicia con mayor peso su práctica política: dicta conferencias, imparte lecciones en la Universidad Popular, escribe artículos, reflexiona sobre la situación mundial y estrecha lazos con los sectores estudiantiles y obreros ${ }^{13}$.

A partir de 1926 emprende un intenso cuestionamiento hacia la Alianza Popular Revolucionaria Americana (APRA) liderada por Víctor Raúl Haya de la Torre. Para 1927, el centro de la disputa se hallaba en la diferencia que ambos pensadores tenían acerca de la situación peruana y sobre el camino político que debían seguir para salir de esa coyuntura. Haya de la Torre, desde una óptica más populista defendía una salida reformista. Por su parte Mariátegui, desde su visión socialista, se inclinaba por una salida revolucionaria. En otras palabras, la diferencia residía en el enfoque diverso con que analizaban la realidad peruana y latinoamericana de la época. Haya sostenía que era necesario configurar una burguesía nacional fuerte capaz de liderar el proceso de modernización del país $y$, a la vez, dispuesta a independizarse del feudalismo interno y del capitalismo internacional. Para ello era necesario un partido popular e interclasista liderado por la burguesía. Dicho partido era el APRA ${ }^{14}$.

Mariátegui, en cambio, sostenía que la burguesía nacional no estaría nunca interesada en realizar una transformación a fondo del país para conseguir una sociedad igualitaria. A mi parecer, esa concepción puede verse reflejada en la disertación ofrecida por Mariátegui en la primera Conferencia Comunista Latinoamericana realizada en Buenos Aires, en junio de 1929. En ella Mariátegui arremete y demuestra la desconfianza a la burguesía criolla. Así lo expresa nuestro autor:

¿Qué cosa puede oponer a la penetración capitalista la más demagógica pequeña burguesía? Nada, sino palabras. Nada, sino una temporal borrachera nacionalista. El asalto al poder por el antimperialismo, como movimiento demagógico populista, si fuese posible, no representaría nunca la conquista del poder por las masas proletarias, por el socia- 
lismo. La revolución socialista encontraría su más encarnizado y peligroso enemigo -peligroso por su confusionismo, por la demagogia-, en la pequeña burguesía afirmada en el poder, ganado mediante sus voces de orden ${ }^{15}$.

Por el fragmento citado, puede sostenerse que para Mariátegui sólo el proletariado aliado con el indigenismo, y organizados en un partido socialista, sería capaz de realizar la revolución que tanto necesitaba la sociedad latinoamericana. En ese sentido, burguesía y pequeña burguesía nada tenían que ver con el nacionalismo, puesto que ambas eran consideradas parte del proyecto imperialista. Sin duda, el antiimperialismo mariateguiano estaba marcado por su filiación marxista; así lo expresa el mismo autor: "somos antimperialistas porque somos marxistas, porque somos revolucionarios, porque oponemos al capitalismo el socialismo como sistema antagónico, Ilamado a sucederlo"16.

En conclusión, la influencia de Mariátegui en el campo intelectual antiimperialista fue muy importante y digna de tener en cuenta. Sus principales aportes, a nuestro parecer, se encuentran marcados por las referencias a la autenticidad del pensamiento hispanoamericano; por su teoría y preocupación indigenista, por su original forma de entender el socialismo, es decir, su heterodoxia marxista; finalmente, por la conjugación de un nacionalismo con una clara visión continentalista.

\subsection{Nacionalismo revolucionario: el caso de la Revolución mexicana y el Aprismo de Víctor Raúl Haya de la Torre}

El nacionalismo revolucionario es una filiación política ideológica que se identifica principalmente con la Revolución Mexicana. Su impacto está ligado al texto de la Constitución de 1917, la cual se caracterizó por tener tres ejes esenciales: la recuperación de las riquezas del subsuelo para la nación, educación para todos e inversión pública.

En efecto, algunos de esos elementos, sobretodo el primero, se identifican por ser próximos a las demandas socialistas de la época; sin embargo, con una fuerte desemejanza: el componente nacional. Evidentemente, dicha filiación es antiimperialista y antioligárquica, pero no abandona la idea de proyecto nacional configurado a partir de la unidad de todos los grupos sociales. En palabras de Francisco Zapata: "en el nacionalismo revolucionario no se puede encontrar el enfrentamiento de las clases como motor del desarrollo social"17. Se trata, pues, de un planteamiento que supone una alianza de clases en la que el Estado se convierte en el eje central 
del desarrollo capitalista y, a la vez, moviliza a los grupos populares para legitimar dicho proyecto.

Así, el planteamiento nacionalista revolucionario no es más que una propuesta unitaria de desarroIlo nacional, caracterizado por ser integrador y antiimperialista. De ahí entonces que las comunidades indígenas lleguen a formar parte de ese plan patrio. Ahora bien, una de los principales impactos del nacionalismo revolucionario mexicano en el continente, y para el caso, en el movimiento antiimperialista, fue el proyecto educacional, que no tenía más propósito que crear nuevos ciudadanos que asumieran y fortalecieran la aspiración renovadora mexicana. Importante papel jugó José Vasconcelos en esta empresa.

En síntesis, la Revolución Mexicana si bien tuvo como reivindicaciones ideológicas el agrarismo, el sindicalismo y la educación, partió de una concepción nacionalista. En otros términos, buscó un proyecto patrio en el que los campesinos (muchos indígenas o de origen indígena) fuesen protagonistas. A partir de esa pretensión político social, es fácil comprender la envergadura que los revolucionarios mexicanos dieron a la educación, pues existía un alto índice de analfabetismo en ese sector poblacional. Según Zapata, "la educación tenía como propósito formar una conciencia revolucionaria en los niños y el sentido de pertenencia a una nación"18.
Asimismo, para construir el país era indispensable contar con una población formada en la técnica, capaz de operar maquinaria y trabajar eficientemente la industria.

En ese sentido, no es nada casual que en El Salvador existiesen grupos de intelectuales que aspiraran a lo mismo; es decir, a la construcción de un país ilustrado e independiente en términos económicos y políticos. De igual manera, no es casual que la intelectualidad salvadoreña viera en Vasconcelos el prototipo de pensador al que había que aspirar. Un ejemplo de ese reconocimiento es una reseña sobre la Raza Cósmica, publicada en la Revista Ateneo de El Salvador en abril de $1926^{19}$. Otro buen ejemplo de esa recepción salvadoreña respecto a las figuras mexicanas, y a la revolución misma, ocurrió en julio de 1929, época en que México se encontraba a la puerta de comicios presidenciales ${ }^{20}$.

A partir de los ejemplos, puede inferirse que uno de los referentes teóricos primordiales del nacionalismo revolucionario es Vasconcelos. Las razones, a mi parecer, radican en que el pensador fue el principal artífice de la revolución educativa y cultural mexicana; y, a la vez, porque consideró la necesidad de unir toda Iberoamérica para poder hacer frente al creciente monopolio que construía Estados Unidos.

Ahora bien, es importante citar al otro referente trascendental 
para tal filiación: Víctor Raúl Haya de la Torre, creador de uno de los movimientos antiimperialistas continentales más importantes de la historia, esto es, la Alianza Popular Revolucionaria Americana (APRA). Efectivamente, entre 1924 y 1926, se fundó dicha organización, según la historiografía aprista fue en la Ciudad de México. Más allá de la fecha exacta, y el debate acerca de su fundación, interesa saber sus fines políticos, que, a mi entender, no era otro que formar una alianza latinoamericana a la que debían pertenecer todos los grupos sociales latinoamericanos que directa o indirectamente sufrían por el imperialismo. Según Jussi Pakkasvirta, "Haya hablaba del "frente único" de intelectuales, obreros y las clases medias proletarizadas. En cada país habría que organizar una célula aprista que siguiera el programa continental desde las condiciones nacionales, aplicando el programa interior o mínimo del APRA"21.

En esa línea, a partir de 1926 el APRA inició un periodo de organización de células y secciones en todo el continente. Respecto a Centroamérica, según Mario Oliva ${ }^{22}$, la referencia de éstas era bastante difusa, lo más probable es que las células apristas se iniciaran con el anuncio y presencia de Haya de la Torre en los países del istmo, hecho que ocurrió hasta el año 1928. Su declive quizás estuvo marcado con la partida del icono peruano en el mismo año.

$Y$ es que en efecto, Haya de la Torre pasó por Centroamérica entre junio y diciembre de 1928. Si bien es cierto, se conoce sobre su estancia en la región, pero muy poco se conoce sobre la verdadera influencia que tuvo en la zona. Para la historiografía aprista, Haya vino a territorio centroamericano para apoyar la lucha de Sandino y unir las organizaciones antiimperialistas latinoamericanas; sin embargo, su estadía no tuvo ninguna acción concreta en ese sentido, de hecho nunca llegó a reunirse con el rebelde nicaragüense.

Así, de Guatemala pasó a San Salvador donde dictó una serie de conferencias antiimperialistas en la Universidad Nacional. De igual manera que en Guatemala, según Ricardo Argueta, Haya fue deportado de El Salvador por su postura antinorteamericana. Así lo indica Argueta:

El pensador visitó El Salvador en 1928, siendo recibido por una multitud de estudiantes, encabezada por los dirigentes de Ageus $^{23} .$. . Haya de la Torre fue invitado a dar una serie de conferencias, las cuales aprovechó para llamar a la juventud a luchar contra el imperialismo, exhortando a los jóvenes a buscar la unidad latinoamericana. La campaña de Haya de la Torre en El Salvador disgustó sobremanera al 
embajador de los Estados Unidos, quien solicitó y obtuvo del doctor Pío Romero Bosque la expulsión del intelectual suramericano y de otros prominentes apristas ${ }^{24}$.

Es interesante destacar el impacto que generó la visita del aprista en los universitarios salvadoreños. En marzo de 1929, el semanario Opinión Estudiantil, después de más de un año de ausencia volvió a editarse; es decir, reapareció como nueva época y con un nuevo cuerpo editor, fungiendo como director el estudiante Alfonso Rochac ${ }^{25}$. La importancia de señalar dicho dato reside en que en el primer número de la publicación se ofrecía el mensaje que Víctor Raúl Haya de la Torre había dictado a los estudiantes salvadoreños seis meses atrás. A continuación se extrae un fragmento de la disertación:

Nuestra tarea común, ahora más que nunca, es la de organizarnos, disciplinarnos y alistarnos conscientemente para cumplir nuestra gran misión de defensores de la libertad de América Latina. ¡Aún tenemos tiempo!.... Nuestros pueblos todos están despertando. La obra siniestra de quienes los han entregado parcial o totalmente a la esclavitud ya ha sido descubierta. Lo urgente es unirnos y organizarnos para defendernos de los traidores de la patria. Lo imperativo es comprender que solo la organización y la disciplina podrán salvar a nuestros pueblos del caos a que se les arrastra ${ }^{26}$.

Finaliza su intervención apelando a la Lucha por la libertad de la región y a figuras libertadoras ame- ricanas, en este caso al padre de la independencia mexicana:

¡Adiós a todos! No olvidaré nunca que la juventud me acompañó hasta el último momento. Así lo diré por el mundo. En la tribuna, en la prensa y en el libro yo clamaré por la libertad de Centro América. Ayudadme y repitamos con Hidalgo, el padre de la libertad mexicana: ¡Viva por siempre nuestra América, abajo los malos gobiernos! ${ }^{27}$

En general, las ideas de Haya de la Torre eran similares a las que propagaban la mayoría de intelectuales progresistas de la época sin vincularse al comunismo internacional. Básicamente las apuestas políticas se concentraban en la unidad latinoamericana, la justicia social, educación para el pueblo y las masas obreras y la alerta ante el peligro imperialista estadounidense. 
Ahora bien, es interesante señalar que la conferencia fue dictada en septiembre de 1928. Días después de su expulsión, se desató una gran polémica ante la salida de Haya de la Torre y otros peruanos apristas de El Salvador. La controversia se originó en Costa Rica cuando Haya expuso que en El Salvador imperaba el terror; dicha expresión tuvo impacto en la prensa salvadoreña, específicamente entre los periódicos El Día y Patria. El último, dirigido por Alberto Masferrer, defendió la postura del aprista, mientras que el primero asumió que la crítica estaba dirigida para todo el país, es decir, no sólo en contra del gobierno salvadoreño; por lo tanto, para El Día se trató de una afrenta hacia todo el pueblo ${ }^{28}$.

En resumen, ideológicamente Haya de la Torre pasó de una posición política pro soviética a ser uno de los principales críticos en la intelectualidad latinoamericana. Por citar un ejemplo de esa transición ideológica, en 1924 escribió un artículo sobre su estancia en Moscú, así lo publicó en la revista costarricense Repertorio Americano: "Hace 20 días que vivo en Rusia, donde he encontrado la revelación de un mundo nuevo. Puedo afirmarte que la revolución rusa es un hecho real, perdurable y firme ${ }^{\prime 29}$. Hacia finales de 1926, Haya percibe la magnitud de la lucha antiestadounidense en América Latina distinguiéndola de la liga antiimperialista, organización vinculada al comunismo internacional. Ya para esos años su antieuropeísmo se dirigió contra el bolcheviquismo y, evidentemente, la tutela que ejercía Moscú en el movimiento obrero internacional ${ }^{30}$. Ahora bien, pese a todo ese viraje, es necesario reconocer que lo fundamental del aporte aprista, y concretamente de Haya de la Torre al movimiento antiimperialista latinoamericano es que logró entender que la izquierda mundial, especialmente la europea, sabía muy poco de la realidad latinoamericana.

\subsection{Unionismo: corriente antimperialista en Centroamérica}

Como se expuso antes, en el siglo XX con la publicación del Ariel de José E. Rodó inició un periodo de reivindicación identitaria en el continente. Dicha defensa se dio en términos de lo propio, esto es: la raza, la cultura y la nación, frente a la penetración agresiva de lo angloamericano. Esa protección se transformó en un tipo de nacionalismo que en la región centroamericana se vinculó fuertemente con el pensamiento unionista, cuya expresión política-de rechazo a las dictaduras y al imperialismo que las apoyaba- representó "la tercera vía" que desplazó de la arena política y social a los otros modelos que pugnaban por la hegemonía: el positivista y el materialista.

Lo interesante de esta respuesta centroamericana es que el unionis- 
mo como planteamiento político no se presentó como una postura pura, sino que fue acompañada de otras corrientes que complementaron o reforzaron la concepción antiimperialista. Para Teresa García Giráldez, el caso del arielismo vino a reforzar la concepción unionista antiestadounidense de la época. Así lo define García Giráldez:

\begin{abstract}
El arielismo refuerza la categoría conceptual del antiimperialismo y de las relaciones entre los pueblos, culturas y razas no subalternas. Es el fundamento de la antítesis a la doctrina por el imperialismo o monroísmo, que producirá en América Latina connotaciones ideológico-políticas -ismos diferentes: el aprismo, el cominternismo, el socialismo utópico, el anarquismo, etc., con un marcado énfasis el unionismo centroamericano espiritualista y vitalista. ${ }^{31}$
\end{abstract}

De ahí entonces que las bases filosóficas e ideológicas del antiimperialismo arielista centroamericano reposen en José Rodó, Rubén Darío, José Martí, Gabriela Mistral y en una serie de pedagogos latinoamericanos cuyo magisterio defendió la idea y la identidad nacional centro y latinoamericana, enfatizando en las historias patrias y en la labor de los próceres que lucharon por la unión regional o continental ${ }^{32}$.

Ahora bien, en esa filiación unionista-antiimperialista con fuerte influencia del arielismo, es clave señalar la figura de Froylán Turcios ${ }^{33}$. A partir de 1922, dirigió desde Honduras la revista Hispano-América, en la cual abordó temas como el de la Unión centroamericana, la oposición raza latina-raza anglosajona y la crítica de los Tratados de Washington ${ }^{34}$. Posteriormente, con su revista Ariel (1925-1928) Turcios se convirtió, a nivel internacional, en uno de los principales defensores de la causa antiimperialista centroamericana. Asimismo, la importancia de Turcios en el terreno político-militante fue trascendental. Se debe tener en cuenta que además de fungir como portavoz del caudillo nicaragüense en la guerra liberacionista (hasta enero de 1928), fue un eslabón entre el arielismo y el aprismo en el intento de enrumbar la lucha de Sandino de lo militar hacia lo político. De hecho, Turcios fue nombrado miembro del APRA para que influyera en Sandino y éste buscara una salida negociada con Estados Unidos, transformando su ejército en partido político ${ }^{35}$.

Por otra parte, se debe recordar que los unionistas centroamericanos, encabezados por el nicaragüense Salvador Mendieta, eran pacifistas y cuestionaban abiertamente el militarismo, entre estos la revolución de Sandino. Evidentemente compartían las causas del caudillo, pero no él método. Para Teresa García, los unio- 
nistas temían a que la radicalidad de Sandino pusiera en peligro el antimilitarismo unionista, "que fue también en cierta medida la causa de ruptura entre Sandino y Turcios" ${ }^{\prime 36}$.

Ahora bien, en El Salvador también existió una corriente de pensadores propiamente unionistasantiimperialistas. Para agosto de
1927 se estableció una organización basada en esa filiación, la cual se denominó: Grupo Nacionalista "La Joven Centroamérica" ${ }^{37}$. Dicha asociación contaba entre sus fundadores a reconocidos intelectuales y periodistas. A continuación, en el cuadro $\mathrm{N}^{\circ} 1$, se detallan los nombres y profesiones de quienes firmaron su primer manifiesto.

\section{Cuadro 1}

Núcleo nacionalista la "Joven Centro América" Comité de Relaciones del Núcleo Nacionalista "La Joven Centro América"

\begin{tabular}{|c|c|}
\hline Nombre & Profesión \\
\hline Napoleón Viera Altamirano & Escritor y periodista (Fundador de El Diario de Hoy) \\
\hline Alfredo Parada & Periodista (Jefe de redacción de Diario El Día) \\
\hline Salvador R. Merlos & $\begin{array}{l}\text { Abogado, escritor y periodista (Miembro de la Liga Antiim- } \\
\text { perialista de San Salvador) }\end{array}$ \\
\hline Adán Funes & Periodista \\
\hline Alberto Masferrer & Escritor y periodista (Fundador en 1928 de Diario Patria) \\
\hline Francisco Morán & Periodista \\
\hline
\end{tabular}

Fuente: Elaboración propia a partir del documento: "Manifiesto del Núcleo Nacionalista "La Joven Centro América", Diario Latino (10936), sábado 13 de agosto de 1927, pp. 1-2.

Dicha agrupación dejaba clara su postura antiimperialista en su primera proclama. Es importante señalar que dicho documento iba dirigido a los "unionistas cen- troamericanos", a quienes, a su vez, llamaban: "compatriotas". De ahí entonces, que el documento caracteriza al istmo centroamericano de la siguiente manera:

En el concepto de las naciones avanzadas del continente Centro América ha dejado de ser una nacionalidad o un grupo de nacionalidades. Centro América es, para el criterio de los pensadores del mundo, una propiedad que el capital extranjero se apresura a comprar o a tomar por las fuerzas de las armas... ${ }^{38}$

Más adelante, el manifiesto señala la situación política, eco- 
nómica y financiera de la región, acusando la entrega de las aduanas centroamericanas a los intereses de banqueros estadounidenses. Asimismo, señala las carencias y limitantes en el ámbito social: educación, salud y vicios como el alcoholismo, entre otros. Finalmente, el documento ofrece el plan de trabajo de la nueva agrupación; que en resumen tienen las siguientes aspiraciones:

Poner en contacto todos los elementos pensantes de Centro América; poner límite al incremento del alcoholismo, la prostitución y el juego; aconsejar la reforma hacendaria de los cinco Estados y la organización de su crédito bancario; organizar la producción agrícola e industrial como un medio de elevar las condiciones de vida a las masas trabajadoras y abrir oportunidades a la acción de nuestro capital; adversar la contratación de empréstitos extranjeros, entre otros ${ }^{39}$.

En definitiva, el documento plantea más proyecciones políticas, económicas y sociales; sin embargo, a mi juicio, las antes citadas son las más importantes y las que reflejan con mayor claridad la postura unionista y antiimperialista. Vale señalar que dicho grupo siguió publicando artículos y comentarios; incluso a partir de septiembre de 1927, "La Joven Centro América" llegó a tener un espacio quincenal en Diario Latino.

En síntesis, la lucha unionistaantiimperialista planteaba una condición de solidaridad contra los intereses foráneos que disolvían el espíritu de la nación centroameri- cana en lugar de orientarlo a los fines de justicia. Por otra parte, el antimperialismo unionista no tenía ninguna animadversión hacia el pueblo estadounidense. En ese sentido, no es descabellado pensar en Alberto Masferrer, figura unionista y antiimperialista, como una muestra de esa actitud asumida por todos estos escritores respecto a Estados Unidos. Conviene citar un ejemplo de esa postura: el 4 de julio de 1928, Masferrer escribió un editorial en ocasión de la celebración de la independencia estadounidense. En dicho texto, el pensador salvadoreño dejaba claro su postura anti empresarial-norteamericana:

Así, el 4 de julio era el día de América, el día panamericano. Entonces no reinaba Wall Street, ni los hombres del norte habían aprendido que las palabras internacionales tienen dos usos, uno para decir y otro para hacer. 
Ahora, el 4 de julio carece de significación fuera de los Estados Unidos, y hasta se nos vuelve difícil no sentirlo como una fecha repulsiva, de recuerdo antipático. Porque la nación que lo conmemora y festeja, no es ya para nosotros una esperanza, ni siquiera una tranquilidad: es la conquista, es el menosprecio, es la absorción ${ }^{40}$.

Evidentemente, la postura masferreriana expresada en la anterior cita refleja que su descontento radicaba más en contra de la política expansionista yanqui. Por otra parte, dicha postura se acerca a la que asumieron los antiimperialistas liberales que fundaron la Liga de San Salvador, aspecto que se abordará en el último apartado.

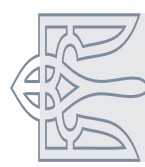

\section{Movimiento antiimperialista en América Latina: Liga Antiimperialista de las Américas (LADLA) y la Alianza Popular Revolucionaria Americana (APRA)}

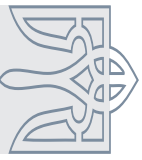

En primer lugar, para iniciar con el estudio sobre la fundación de la Liga Anti-Imperialista de San Salvador, se debe partir del contexto político y social a lo largo del territorio americano. Dicho entorno fue marcado por el aumento de la intervención estadounidense en Nicaragua y en otros países, así como el rechazo por parte de distintos sectores sociales y políticos latinoamericanos. En esa línea, es oportuno destacar la fundación de las organizaciones matriz del movimiento antiimperialista del continente. Efectivamente, primaron dos grandes corrientes: una vinculada a la Internacional Comunista, Comintern; es decir, con una propuesta ideológica socialista; y otra con una fuerte tendencia reformista -en relación a la estrategia y los principios sostenidos por la In- ternacional Comunista- para enfrentar al imperialismo estadounidense: la Alianza Popular Revolucionaria Americana (APRA).

Respecto a la primera organización, la Liga Antiimperialista de las Américas (LADLA), cuyos brazos llegaron a todo el continente, surgió como un intento del Comintern en su deseo de crear una organización idónea para protestar y denunciar la presencia colonial e injerencia de Estados Unidos en la región. De igual manera, marcaron un claro sentido de filiación y respaldo a la Unión Soviética en sus primeros años de revolución. Se trató, pues, de una estrategia frentista capaz de aglutinar a todas las corrientes antiimperialistas de la época. En palabras de Daniel Kersffeld:

\section{A partir del $V^{\circ}$ Congreso (del Comintern) en 1924, es que pronto la Liga Antiimperialista, como entidad periférica u}


organización de apoyo a los partidos comunistas, se dio a la tarea de nuclear, principalmente, a aquellos representantes de las burguesías progresistas que veían con preocupación el expansionismo colonial sobre la región y que al mismo tiempo brindaban su apoyo al proceso revolucionario ruso. Así, y en una organización que, por lo menos hasta fines de la década de 1920 evitó aparecer públicamente como demasiado roja, se agrupaban en torno a ella artistas e intelectuales y, junto a ellos, estudiantes universitarios, trabajadores urbanos y dirigentes campesinos y agraristas los que, más allá de las diferencias, mantenían en cambio un fuerte sentido de identidad y de pertenencia en común. ${ }^{41}$

En ese sentido, desde principios de 1925, año de fundación de la LADLA en la Ciudad de México, el movimiento antiimperialista latinoamericano se fue suscribiendo desde varias sedes en distintos países. Además de México, donde se encontraba la sección central, se coordinó con la sección estadounidense. De igual manera, la Liga se articuló en Argentina, Cuba, Brasil, Uruguay Chile, Puerto Rico, entre otros. El Salvador no fue una excepción, tal como se verá más adelante. Ya para finales de los años veinte, la estrategia frentista empezó un declive generalizado por la radicalización de los partidos comunistas. Radicalización que provenía como lineamiento político desde Moscú. Fue entonces que a partir de esa decisión se empezaron a desactivar las organizaciones que tenían como misión recabar apoyos entre los grupos burgueses y las clases medias. Entrada la década de los años treinta, se constituyó una nueva estrategia: frentes antifascistas ${ }^{42}$.
En resumen, la historia de la LADLA desde su fundación -finales de 1924 y principios de 1925- hasta su desaparición, diez años después, no fue más que la historia del movimiento comunista en ascenso. Se trató, pues, de una corriente antiimperialista cuya influencia o sustento teórico estaba basado en el marxismo-leninismo que, ciertamente, fue más comprendido desde la praxis política que desde una producción teórica, a pesar de que sus distintas filiales contaron con un medio impreso para divulgar sus ideas.

La otra organización que ganó peso en el continente fue el APRA, encabezado por Víctor Raúl Haya de la Torre. Es interesante señalarla porque ambas organizaciones contaron con adeptos en El Salvador. De igual forma que la anterior organización, el movimiento político aprista surgió en la década de los años veinte. Según su historia oficial, apareció también en México 
en diciembre de 1924, "cuando los cinco puntos generales de su programa fueron enunciados: acción contra el imperialismo yanqui; la unidad política de América Latina; la nacionalización de tierras e industrias; la internacionalización del Canal de Panamá; finalmente, la solidaridad con todos los pueblos y clases oprimidas del mundo"43.
Sin embargo, pese a la información que se conoce respecto a la fundación del APRA, Kersffeld sostiene que existe un mito sobre su nacimiento. Según este autor, el dato contrasta con las referencias históricas que permiten dar cuenta de su aparición como núcleo constituido durante el periodo que va desde los últimos meses de 1926 hasta principios de 1927. Así lo señala Kersffeld en su investigación:

Según Pedro Planas, apenas en octubre de 1926 un grupo de cuzqueños residentes en París y miembros de la AGELA (del que por aquel entonces también formaba parte Eudocio Ravines) se reunió en un café con Haya de la Torre y dieron vivas al APRA y América Latina. El 22 de enero de 1927, a menos de un mes de que comenzara el Congreso, Haya los reunió nuevamente con el propósito de fundar oficialmente la sección, que estuvo a cargo del propio Ravines ${ }^{44}$.

Pese a la posición ideológica que en un principio mostró el APRA, cercanas a algunas ideas socialistas $^{45}$, fue duramente cuestionado cuando su ideólogo, Haya de la Torre, polemizó con las tesis leninistas sobre el imperialismo. Una de las principales críticas al marxismoleninismo era su eurocentrismo; de ahí entonces que para el pensador aprista las consideraciones de Lenin funcionaban en los países industrializados, pero en el espacio tiempohistórico indoamericano todo era diferente. Según Jussi Pakkasvirta, Haya afirmó que el capitalismo llegó a Indoamérica con el imperialismo. Por lo tanto, "en su teoría sobre el imperialismo, este último era la primera fase del capitalismo porque sólo después de la invasión del capital extranjero, desde el fin del siglo XIX, el capitalismo pudo desarrollarse de verdad en América Latina" ${ }^{\prime \prime 6}$.

De hecho, para 1927 y 1928, sus ideas prosoviéticas mermaron para convertirse al indoamericanismo, logrando una postura antieurocéntrica $y$, de paso, contraria a la tutela que ejercía Moscú sobre el movimiento obrero latinoamericano. Dicha postura serviría a los antimperialistas y militantes comunistas para tildarlo, al igual que a 
Sandino, como traidores nacionalistas o reformistas.

Ahora bien, la ruptura entre ambas organizaciones se dio en el Congreso de Bruselas de 1927. El punto de quiebre fue la Resolución sobre América Latina que derivó del cónclave. Si bien dicha solución fue uno de los más importantes logros de la LADLA en el sentido que concretó un frente con un buen número de organizaciones políticas y sindicales, implicó al mismo tiempo la mayor disputa con el APRA, pues los delegados de la última -Haya de la Torre y Eudocio Ravines- firmaron con reservas el documento ${ }^{47}$.

En otras palabras, a partir de Bruselas inició una nueva relación para las dos organizaciones antiimperialistas más importantes del Continente. La cercanía con los partidos comunistas terminó convirtiéndose en un eje diferenciador fundamental: "A partir de ese momento, re- sultaba claro que Haya de la Torre optaba por la construcción de un movimiento autónomo latinoamericano, sin ninguna intervención e influencia extranjera" ${ }^{48}$; a diferencia de la LADLA que, pese a su negación, figuraba como una creación del Comintern.

Ahora bien, interesa conocer y comprender la ruptura entre la LADLA y el APRA, puesto que la Liga Anti-imperialista de San Salvador, de acuerdo a sus documentos, y tal como se verificará más adelante, estaba más cercana ideológicamente a la segunda. Esto a raíz del fuerte talante liberal de sus miembros fundadores $y$, principalmente, por la afinidad de sus exigencias políticas. En ese sentido, conviene dejar bien claro en qué consistió esa reunión antiimperialista de Bruselas y cómo influyó a las organizaciones antiestadounidenses salvadoreñas. A continuación se detallan algunos aspectos del citado Congreso.

\section{Congreso de Bruselas: punto clave para la ruptura antiimperialista}

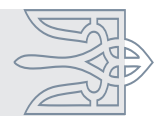

Entre el 10 y 15 de febrero de 1927 en el Palacio de Egmont, Bruselas, se celebró el Congreso Mundial contra el Imperialismo y la Opresión Colonial, cuyo organizador fue Willi Münzerberg, creador de las organizaciones antimperialistas periféricas. El objetivo del Congreso no era otro "que ampliar las redes de apoyo entre los distintos continentes y vincular otras entida- des que, como la Liga Antiimperialista de las Américas, funcionaban de manera más bien autónoma con respecto a otros frentes de lucha anticolonialista" ${ }^{49}$.

Según Daniel Kersffeld, en su acuciosa investigación sobre la historia de la LADLA, ésta se adhirió a dicha reunión por medio de sus secciones de Argentina, Cuba, Mé- 
xico, Nicaragua, Perú, Panamá, El Salvador, Venezuela, Estados Unidos y del Comité Continental de Organización. Como delegados de la Liga asistieron Julio A. Mella (quien representó a las secciones mexicana, salvadoreña y panameña); Leonardo Sánchez (Cuba); Gustavo Machado (sección nicaragüense); Víctor Raúl Haya de la Torre (sección peruana y panameña); Carlos Quijano (sección venezolana), Eudocio Ravines y Manuel Gómez (sección argentina y estadunidense, respectivamente $)^{50}$.

Es importante señalar que en todos los países periféricos existía una lucha frente a la ocupación extranjera. En el caso latinoamericano la reacción antiimperialista se generó frente a las prácticas que Estados Unidos realizaba en México y fundamentalmente en Nicaragua. De hecho, el Congreso recibió apoyo político y económico del presidente Plutarco Elías Calles, quien le interesaba demostrar que tenía fuerza y respaldo frente a las ambiciones de Estados Unidos. Según Kersffeld, el presidente mexicano propuso a su embajador en Alemania, Ramón De Nigri, de muy buena relación con los comunistas, para formar parte del Comité Organizador del Congreso ${ }^{51}$.

Efectivamente, el objetivo del cónclave era servir de punto de encuentro entre todas las organizaciones antiimperialistas y anticolonialistas del mundo ${ }^{52}$. Por su parte, La LADLA, a través del órgano de difusión del Partido Comunista Mexicano, El Machete, consideraba que la importancia de dicho evento radicaba en la unión del movimiento antimperialista ${ }^{53}$. De igual manera, la liberal Liga Anti-imperialista de San Salvador también consideró importante el mencionado Congreso. En el mes de diciembre se publicó en Diario Latino una nota informativa sobre la próxima sesión de la Liga en la cual solicitaba a sus miembros puntualidad, pues el objetivo de la sesión era determinar al delegado para la reunión antiimperialista $^{54}$.

Ahora bien, durante el mes que se realizó el Congreso no se encontró ningún documento de la Liga relacionado directamente al respecto. No obstante, Diario El Día publicó un cable de México en el que señalaba el papel que desempeñó José Vasconcelos durante su participación en Bruselas ${ }^{55}$.

Retornando al estudio sobre el Congreso, su Comité Organizador quedó integrado de la siguiente manera: Münzerberg, Henri Barbuse, Hawaharlal Nehru, en tanto que de América Latina participaron Ramón de Negri, José Vasconcelos, Manuel Ugarte, Luis Casabona y César Falcón. Ugarte y Vasconcelos representaron el lugar preponderante de los intelectuales en su apoyo a las luchas nacionalistas y anticoloniales. Por parte de la LADLA, el único apoderado fue el periodista César Falcón (cofundador, junto con José 
C. Mariátegui, de la primera célula comunista peruana $)^{56}$.

Se debe señalar que fueron 164 delegados a la reunión de Bruselas, provenientes de más de cien países coloniales y semicoloniales. A la vez, representaban una diversidad de filiaciones ideológicas; se trataba, pues, de izquierdistas, socialdemócratas, nacionalistas y liberales. No obstante, pese a algunas figuras reconocidas como comunistas, tal es el caso de Julio Antonio Mella, no hubo nadie que representara oficialmente a algún partido comunista. Sin embargo, para Kersffeld, a pesar de la discreción de los comunistas para no alejar a los sectores más liberales, no fue suficiente para que las organizaciones socialdemócratas boicotearan el Congreso acusándolo de ser una simple estratagema por parte de Moscú ${ }^{57}$.

En definitiva, la importancia del Congreso antiimperialista va más allá del momento histórico en que se realizó. Para América Latina significó el culmen de la ruptura en el movimiento izquierdista antimperialista, es decir, en la estrategia de frente único. Así, para Kersffeld: "pese a los éxitos de la LADLA, una sorda disputa detrás de la escena con el APRA marcaría los límites de la política del frente único y dejaría expuesta, por primera vez de manera evidente, la lucha interna por la dirección del antimperialismo en América Latina" ${ }^{\prime 28}$.
Por otro lado, para efectos de la presente investigación, interesa revisar la historia del movimiento antimperialista argentino después de Bruselas, pues sus organizaciones entraron en un duro debate. Conviene señalar el caso argentino puesto que un sector de éste entablaría vínculos con el movimiento antimperialista salvadoreño a través de Diario Latino y su director, Miguel Pinto. En ese sentido, la fuerte presencia comunista de la LADLA y la existencia de una de sus nuevas filiales en Argentina dio motivos para que Haya de la Torre le propusiera a Alfredo Palacios, presidente de la Unión Latinoamericana (ULA), la conformación de una alianza estratégica.

Según Kersffeld, ese nuevo alineamiento entre la ULA y el APRA creó una nueva división: con el giro aprista de la ULA y cada vez más enfrentado con su presidente, Alfredo Palacios, Arturo Orzábal Quintana decidió emprender su propio camino y, con un grupo de militantes antiimperialistas, fundó en mayo de 1927 un nuevo agrupamiento político: la Alianza Continental (AC) ${ }^{59}$. Se trato de una organización que mantuvo buenas relaciones con el Partido Comunista Argentino, sobre todo en torno a la defensa de Moscú y del movimiento de Sandino en Nicaragua. Pese a que no llegó a tener la importancia de otras organizaciones, su existencia sirvió para dar cuenta de los reacomodamientos que cada vez con mayor intensidad 
se irían produciendo durante los últimos años de la década en la izquierda local ${ }^{60}$.

Si bien Alianza Continental se fundó en mayo de 1927, fue hasta agosto de ese año que en El Salvador se publicó información sobre la nueva organización. El 26 de agosto, Diario Latino publicó un editorial del periódico argentino La Prensa en la que presentaba un resumen del manifiesto de la organización en cuestión. Junto a la nota, se publicó también una invitación a Miguel Pinto para acuerpar dicho lanzamiento $^{61}$. En resumen, lo que plantea el manifiesto, según el editorial de La Prensa, es un proyecto político de unión latinoamericana contra todo tipo de injerencia, no importando de qué potencia se tratase:

El programa de acción que preconiza la Liga es amplio y de vastos alcances, como que tiende desde la efectiva independencia de algunas naciones de Centroamérica, que se encuentran con sus facultades soberanas limitadas, hasta la proclamación de un nuevo derecho latinoamericano de no agresión, de no intervención, de no participación en los conflictos suscitados entre naciones extranjeras; de reintegración de las Malvinas a nuestro país, de todo aquello, en dos palabras, que reconozca la absoluta soberanía y la integralidad territorial de las naciones latinoamericanas ${ }^{62}$.

Un día después, el 27 de agosto, Latino publicó el manifiesto completo de Alianza Continental, el cual ciertamente expresa la propuesta de un nacionalismo continentalista:

Tan sólo la unión espiritual, económica y política, organizada sin pérdida de tiempo con un audaz criterio de nacionalismo continental, puede alejar la amenaza que se cierne sobre nuestros países ${ }^{63}$.

Es interesante señalar el texto introductorio del Manifiesto que Diario Latino redactó, el cual sostiene que se trata de una organización "para impulsar el desarrollo de un nacionalismo integral de la América Latina" ${ }^{\prime \prime 4}$. Y es que es entendible que el periódico salvadoreño publicara dicho manifiesto, pues a pesar que Alianza Continental tenía fuerte vínculos con el movimiento obrero argentino, su postura era más anti políticas financieras norteamericanas y en pro de la soberanía de los países del continente. En otros términos, estaba lejos de suscripciones a otra organización antimperialista y menos al movimiento comunista internacional. Así lo refleja el siguiente extracto de sus propósitos: 
No nos mueven sentimientos de hostilidad hacia Estados Unidos ni hacia ningún otro pueblo extranjero. El nacionalismo integral que auspiciamos como base de la futura alianza de nuestros pueblos, es la condición previa de un aporte real, no ilusorio, de la América Latina al progreso moral y jurídico del mundo. Sin la soberanía plena de todas nuestras naciones, carecería de sentido o tornaríase peligroso para nosotros, el noble lema de 'América para la Humanidad'65.

Sin lugar a dudas, lo que Alianza Continental ofreció al movimiento antimperialista de la región fue un nacionalismo continental basado en siete principios y en un programa de catorce puntos ${ }^{66}$. Dichos principios claramente compartirían el mismo espíritu del ideario mostrado en el manifiesto fundacional de la liberal Liga Anti-Imperialista de San Salvador.

Finalmente, el influjo que tuvo Bruselas en el plano centroamericano, a juicio de Kersffeld, fue la consolidación de algunas secciones latinoamericanas de la LADLA, entre éstas la de El Salvador:

Su fortalecimiento en la capital del país y en varias ciudades al interior fue resultado de la campaña de apoyo sandinista, organizada en comités de campesinos y artesanos dedicados a la recaudación de fondos y al reclutamiento de voluntarios para la guerrilla, así como de las masivas protestas contra el imperialismo y el apoyo a distintas empresas, una de ellas la revista El Grito de la Raza, virtual vocera de la sección, editada por el exiliado nicaragüense José Constantino González ${ }^{67}$.

No obstante, por las fuentes consultadas para el presente artículo, y como se demostrará en el siguiente apartado, Kersffeld hace referencia en su investigación no al sector salvadoreño de la sección centroamericana de la LADLA, sino a la Liga Anti-imperialista de San Salvador, pues su descripción se asemeja a las labores que la última publicaba en la prensa salvadoreña. Por otra parte, Constantino González fungió como Secretario de la liga liberal al menos hasta 1927.
En síntesis, no se puede entender todo el funcionamiento y la razón de ser de la Liga Antiimperialista de San Salvador sin su contexto. Sin duda, la realidad centroamericana influyó a su fundación, pero el contexto mundial y, primordialmente, latinoamericano ayudo a legitimar las ideas y proyecciones que se gestaban en El Salvador. En ese sentido, no cabe ninguna duda que las ideas más progresistas circulaban de norte a sur teniendo eco en el centro del continente. 
Ahora bien, una vez expuesto todo el contexto político que envolvió al movimiento antimperialista de la región, pasaremos al análisis de la Liga liberal de San Salvador, su fundación, sus principios y sus actividades.

\section{Caracterización de Liga Anti-Imperialista de San Salvador: ideario y actividades políticas en el periodo fundacional}

\subsection{Fundación de la Liga Antiimperialista de San Salvador}

Como se señaló antes, en América Latina el movimiento antimperialista empezó a organizarse a partir de 1924, lo cual no excluye la existencia de asociaciones u organizaciones predecesoras. En El Salvador una liga antimperialista fue fundada en noviembre de 1926. Una de las principales razones de su fundación fue la preocupación ante la política intervencionista estadounidense en Nicaragua. Para el historiador Carlos Gregorio López Bernal, algunos de los fundadores de la Liga eran cercanos a las organizaciones obreras, por ello sostiene que las acciones que desarrolló dicha asociación estuvieron muy relacionadas con la Federación Regional de Trabajadores de El Salvador (FRTS) ${ }^{68}$ y coadyuvaron a ganar adhesiones para la última ${ }^{69}$.

En concreto, el domingo 21 de noviembre de 1926, en casa del nicaragüense Rosendo Argüello, se constituyó la Liga Anti-Imperialista de San Salvador cuyo planteamiento principal era trabajar por los derechos de los pueblos de Hispanoamérica. Así lo refleja la primera noticia acerca de su fundación:

Dicha Liga, como se deja ver con el nombre, trabajará porque los derechos de los pueblos hispanoamericanos, sean respetados por aquellos que tratan de exterminar la tradición, las costumbres y hasta la vida propia de cada país.

Su extensión, abarcará toda la América Latina, creando asociaciones con idénticos fines. Es tiempo ya de que los pueblos de habla española en América tengan una manera defensiva de la garra sobornadora y exterminadora de otros países ${ }^{70}$. 
Por su parte, La Prensa también publicó, el mismo día, la noticia sobre la nueva organización:

Desde un punto de vista muy elevado, se ha fundado en esta capital una Liga Anti Imperialista, nombre que por el momento se le da, compuesto de personas que tratan por medio de campañas espirituales, declarar una franca oposición a todo lo que llegue del extranjero en forma de conquista, aunque sean pacíficas. El decir, una defensa de los intereses latinoamericanos de las absorciones directas que ya en una forma o en otra se proponen destruir nuestra tradición, nuestras leyes, nuestras costumbres, nuestros procedimientos heroicos, y todo aquello a lo que tenemos absoluto derecho ${ }^{71}$.

Es interesante destacar que estas primeras palabras ofrecen elementos para inferir que se tratará de una organización ligada a la corriente arielista o unionista, pues el hecho de realizar campañas espirituales y el énfasis en la custodia de lo propio, deja claro que su interés va orientado a defender la soberanía no sólo política y económica, sino también moral y cultural. Por otra parte, es interesante distinguir que en la constitución de la Liga, sus fundadores plantearon que sus fines no estarían vinculados a la política local, es decir, no se inmiscuirían en la realidad política salvadoreña. Probablemente dicha aclaración fue necesaria puesto que alrededor de ocho fundadores de la Liga eran de origen extranjero, específicamente nicaragüense ${ }^{72}$. Asimismo, el impreso notifica la designación de la directiva provisional de la Liga, que a continuación se muestra en el cuadro $\mathrm{N}^{\circ}$ 2. Dicha nómina quedó integrada por notables profesionales y hombres vinculados a la literatura.

\section{Cuadro 2}

\section{Liga Anti-Imperialista de San Salvador} Directiva provisional

\begin{tabular}{l|l|l}
\multicolumn{1}{c|}{ Cargo } & \multicolumn{1}{|c}{ Nombre } & \multicolumn{1}{c}{ Nacionalidad } \\
\hline Presidente & Miguel Pinto & Salvadoreña \\
Vicepresidente & Dr. Rosendo Argüello & Nicaragüense \\
\hline Primer Vocal & Dr. José de Jesús Zamora & Nicaragüense \\
\hline Tercer Vocal & General J. Ernesto Alvarado & No se conoce \\
\hline Segundo vocal & Dr. Salvador R. Merlos & Salvadoreña \\
Cuarto vocal & Luis Vega B. & No se conoce \\
Quinto vocal & Leonardo Montalván & Nicaragüense \\
\hline
\end{tabular}




\begin{tabular}{l|l|l|}
\multicolumn{1}{|c|}{ Cargo } & \multicolumn{1}{|c|}{ Nombre } & \multicolumn{1}{c|}{ Nacionalidad } \\
\hline Tesorero & José A. Navarro & No se conoce \\
\hline Fiscal & José Dutriz & Salvadoreña \\
\hline Secretario & J. Constantino González & Nicaragüense \\
\hline Secretario & Juan José Fernández & Salvadoreña \\
\hline Otros fundadores & Juan Felipe Toruño & Nicaragüense \\
& Agenor Argüello & Nicaragüense \\
& Eliseo Lacayo Fernández & Nicaragüense \\
& Ángel F. Plazaola & Nicaragüense \\
& Leandro Espinoza h. & No se conoce \\
& D. Martínez Reyes & No se conoce \\
& Eusebio Real & No se conoce \\
& José Lacayo Téllez & Nicaragüense \\
\hline
\end{tabular}

Fuente: Elaboración propia con base en: (1) "Se ha organizado una Liga Anti-Imperialista", La Prensa (4506), martes 23 de noviembre de 1926, p. 4; (2) "Se ha fundado en esta capital la asociación nicaragüense", Diario Latino (10958), jueves 8 de septiembre de 1927, p. 1.

Por otra parte, la nota publicada por Diario Latino también expone el acta que se levantó en dicha sesión.

Para efectos de aproximación al ideario político de la Liga, conviene mostrar el siguiente fragmento:

El objeto de la presente reunión es formar una Liga AntiImperialista que se oponga a los actos atentatorios contra la autonomía de los pueblos hispanoamericanos y a toda clase de absorción aunque se desarrolle en forma pacífica.

La Liga a su vez, promoverá la fundación de asociaciones de igual índole y cultivará relaciones de las entidades que alienten iguales anhelos ${ }^{73}$.

Finalmente, también informa sobre el acuerdo de un libro para firmar adhesiones que simpaticen con el nuevo movimiento; $y$, a la vez, el propósito de lanzar un manifiesto exponiendo el ideario de la agrupación. Los intelectuales Salvador Ricardo Merlos y Rosendo Argüello fueron los encargados de elaborar el manifiesto inicial.
Así, entre noviembre de 1926 y marzo de 1927 se puede considerar como un periodo álgido en el contexto latinoamericano, fundamentalmente para el movimiento antimperialista. Como se expresó en el anterior acápite, entre los meses antes señalados se realizó el Congreso de Bruselas, evento que cautivó a la gran mayoría de los 
movimientos antimperialistas y de liberación nacional a nivel mundial y regional. Por otro lado, la invasión en Nicaragua, por parte de Estados Unidos, cada vez se consolidaba más; en definitiva, todos esos factores propagaron el espíritu antimperialista a lo largo del continente. En ese contexto, constantemente se publicaban en los periódicos más importantes de la capital noticias, manifiestos, informes y convocatorias de la Liga Antiimperialista de San Salvador, es decir, la liga de raíz liberal.

En esa línea, un día después de la publicación sobre la fundación de la Liga, se divulgó una nota sobre la segunda sesión de ésta. Entre los principales aspectos que señalaban se encontraba la lectura de comunicaciones y telegramas de adhesión al movimiento y el acuerdo de enviar telegramas a los presidentes de Guatemala, Costa Rica y México por su actitud honrosa frente a la situación nicaragüense ${ }^{74}$.

Por otra parte, entre el sábado 27 y martes 30 de noviembre se publicaba en al menos tres periódicos (El Día, La Prensa ${ }^{75}$ y Diario Latino $^{76}$ ) el Manifiesto de la Liga Anti-Imperialista de San Salvador a los pueblos Ibero-Americanos, el cual afirmaba:

Nuestros antepasados lucharon heroicamente por un gran ideal, el ideal de forjar nacionalidades con personería propia que pudieran gozar de la vida soberana que por derecho natural les corresponde en el concierto de los pueblos libres ${ }^{77}$.

Seguidamente, enumeraba todos los agravios que los pueblos de Hispanoamérica habían enfrentado a raíz de la política intervencionista estadounidense, entre las cuales destacan: las interpretaciones antojadizas de la Doctrina Monroe, obs- táculos a la unión centroamericana, ocupación de Puerto Rico, conquista de la mitad del territorio mexicano, lesiones a la soberanía de Panamá, intervenciones de todo orden en los asuntos interiores de Nicaragua, etc., para terminar afirmando:

Ninguna nación en el mundo nos ha causado tanto daño material y moral como la de los Estados Unidos del Norte. Ella no se ha preocupado más que de enriquecerse con nuestro oro y engrandecerse con nuestras tierras sin tomar en cuenta la justicia y el derecho de los débiles ${ }^{78}$.

El mismo documento asegura que no es una lucha contra el pueblo mismo de Estados Unidos, sino contra sus rapaces capitalistas. Así se puede resumir en el siguiente párrafo: 
A pesar de ser nosotros las víctimas propicias de esa rapacidad monstruosa, comprendemos perfectamente que son los magnates de Wall Street-judíos sin Dios ni conciencia, que trafican con la sangre y con las lágrimas de la humanidadlos mayores culpables de nuestras desgracias ${ }^{79}$.

El Manifiesto concluye exponiendo la que sería su brújula política, esto es, su interés por

defender la autonomía de los pueblos y el espíritu de la modernidad ilustrada:

Al comenzar la Liga esta campaña ajena en absoluto a las contiendas de la política local, no hace sino entrar en la corriente de ideas modernas que agitan la conciencia de la humanidad. El espíritu de la autonomía inflama los corazones y los pueblos aherrojados buscan el camino de su redención...

Esta LIGA, al colocarse ante el imperialismo avasallador, tiene la más firme convicción de que no serán vanos sus intentos y poseída del optimismo que generan las causas nobles, hace un enérgico llamamiento a todos los hombres de buena voluntad, para que mediante la creación de organismos similares, cooperen en la obra de defensa racial ${ }^{80}$.

Sin duda, al estudiar el Manifiesto queda claro que el fin político de la organización naciente no era otro que la defensa de la soberanía de todos los países del continente. En otras palabras, a partir de dicho documento puede separarse la Liga capitalina, recién fundada, de los fines y objetivos de la LADLA. Si bien es cierto, la última estaba a favor de la emancipación y autonomía de los pueblos latinoamericanos, igualmente tenía un interés que iba más allá de la lucha antiimperialista: legitimar y apoyar a la Unión Soviética y, a la vez, la lucha por el comunismo internacional. Ahora bien, pese a esa distinción, y para despejar toda duda acerca del movi- miento antimperialista salvadoreño, es importante mostrar también la otra Liga cuyas ideas fueron retomadas del movimiento cominternista.

\subsection{Caracterización de la LADLA en El Salvador}

El 31 de diciembre de 1926, Diario Latino publicó una comunicación de la LADLA sector salvadoreño. Además de la comunicación y el saludo, el periódico también publicó las bases de la Liga Antiimperialista de las Américas a las que debía ceñirse el secretariado salvadoreño. La salutación y el motivo del texto quedaron expresados de la siguiente manera: 
Señor Director de Diario Latino

Presente:

Señor:

Tenemos la honra de poner en su conocimiento las bases a que se ceñirá en sus labores el SECTOR SALVADOREÑO SECCIÓN DE CENTROAMERICA DE LA LIGA ANTI-IMPERIALISTA DE LAS AMÉRICAS, para que si lo tiene a bien se sirva en publicarlas en el diario de su dirección ${ }^{81}$.

Por otra parte, dentro de los considerandos que presenta el documento, la mayoría están en sintonía con los agravios expuestos en el manifiesto de la Liga de San
Salvador; sin embargo, el cuarto considerando tiene una jerga y un horizonte más cercano a la tradición marxista-leninista, propia de la época:

ch) que el capitalismo ha llegado a la última fase de su desarrollo -el Capitalismo Imperialista- esta dando expresión o una nueva forma de asociación hermana de la cual resultan las Federaciones de Repúblicas Obreras y Campesinas del Continente Americano sin amos y esclavos, sin explotadores ni explotados ${ }^{82}$.

A partir de esas premisas, la LADLA sector salvadoreño anunciaba al país la constitución de dicha organización, cuya sede central estaba en la Ciudad de México. A la vez, mostraba sus líneas de acción, separando la proyección en aspectos internacionales y lo- cales, tomando en cuenta que en el ámbito local se refieren a toda Centroamérica. A continuación, se transcriben los principales puntos del programa de acción expuesto. En el plano internacional, la LADLA sección salvadoreña se planteaba emprender las siguientes acciones:

a) Formar un frente único de todas las fuerzas antimperialistas dispersas que existen en las Américas para contrarrestar el imperialismo de Estados Unidos de América y de cualquier otro que amenace con destruir la cultura que empieza a esbozarse en nuestro continente.

b) Luchar por la independencia de Filipinas y Puerto Rico. 
c) Dar ayuda a los pueblos dominados por las Naciones Imperialistas, sean de Europa, Asia, América u Oceanía.

ch) Combatir las adquisiciones de nuevas bases estratégicas por las Potencias Imperialistas y procurar la reintegración de las existentes a sus respectivas soberanías.

d) Internacionalización del Canal de Panamá.

e) Sostener cordiales relaciones con todas las Instituciones Anti Imperialistas del Mundo.

f) Luchar por la abolición de la Enmienda Platt de la Constitución de Cuba.

g) Combatir los avances del Imperialismo de Wall Street en cualquier parte de América ${ }^{83}$.

Por otra parte, desde el ámbito la liga cominternista se suscribía a nacional, el sector salvadoreño de las siguientes labores:

h) Formar un frente compacto de todas las fuerzas Anti imperialistas que existen en las Repúblicas de Guatemala, Honduras, Nicaragua, Costa Rica y Panamá; pudiendo estar incluida la Colonia Inglesa de Belice, si ella no se adhiere a la Sección Mexicana. Dichas fuerzas están constituidas por obreros, campesinos, estudiantes e intelectuales de vanguardia y de más personas de ideas antiimperialistas.

i) Difundir por medio de conferencias, periódicos, volantes, folletos, etc., los fines locales de la Liga Anti Imperialista de las Américas.

j) Procurar la nacionalización de los ferrocarriles y demás empresas de servicios públicos y evitar que sean otorgadas nuevas concesiones a las Compañías Imperialistas.

k) Denunciar el sistema de expansión empleado por el Imperialismo Yanqui para sobornar nuestros países.

I) Conseguir condiciones favorables de trabajo a los agricultores centroamericanos en las zonas bananeras que se 
encuentran actualmente dominadas por las Compañías Imperialistas que han monopolizado dichas zonas.

m) Solidarizarse con todo movimiento anti-imperialista que sea emprendido por cualquier institución o Sociedad Centroamericana

n) Ayudar en la organización de los Sectores que aún no estén organizados en la sección de Centroamérica ${ }^{84}$.

Otra información interesante que ofrece la publicación, es la estructuración organizativa del secre-

tariado salvadoreño. Evidentemente, compuesto con significativa representación del proletariado nacional:

\section{Cuadro 3}

Liga Anti-Imperialista de las Américas Sección de Centroamérica Secretariado sector de El Salvador

\begin{tabular}{l|l}
\multicolumn{1}{c|}{ Cargo } & \multicolumn{1}{c}{ Nombre } \\
\hline Secretario General & Bachiller Manuel de Jesús Mena \\
Secretario de la Sección de Obreros y Campesinos & Manuel A. Leiva \\
$\begin{array}{l}\text { Secretario de la Sección de Estudiantes e Intelectuales de } \\
\text { vanguardia }\end{array}$ & Bachiller Alfonso Rochac V. \\
$\begin{array}{l}\text { Secretario de la sección femenina } \\
\text { Secretario de Actas }\end{array}$ & Concepción Anaya \\
Secretario Financiero interino & Simón Zapata \\
\hline
\end{tabular}

Fuente: Elaboración propia con base en: "Bases de la Liga Anti-Imperialista de las Américas", Diario Latino (10754), viernes 31 de diciembre de 1926, p.2.

Sin lugar a duda, el interés de la organización cominternista va más allá del asunto en Nicaragua. Para la Liga liberal, dicho conflicto sí aparece como una referencia importante en su manifiesto fundacional, pues para ellos la democracia en el país de los lagos era en realidad un humillante tutelaje de Estados Unidos; a la vez, culpan a éste de todas las intervenciones en los asuntos internos de Nicaragua. De ahí entonces que sugieran repudiar y combatir al Gobierno de Adolfo Díaz. En cambio, el secretariado salvadoreño de la LADLA no tiene una mención exclusiva y directa sobre el problema nicaragüense. En otras palabras, el conflicto en el país centroamericano, que en ese momento se encontraba en la transición de ser una guerra constitucionalista -entre liberales y conservadores- a una invasión estadounidense, no resultaba tan apremiante como para ser un detonante fundacional de la organiza- 
ción, como sí ocurrió en el caso de la liga liberal. A todas luces, puede interpretarse que la liga de raíz cominternista en El Salvador se fundó en el marco de la estrategia frentista de la LADLA y no como respuesta a un hecho específico: la intervención norteamericana en Nicaragua.

En ese sentido, resulta adecuado hacer una distinción respecto a la información que ofrece Daniel Kersffeld en su investigación sobre la LADLA y sus sedes en todo el continente. A juzgar por nuestras fuentes, Kersffeld aparentemente cae en un desacierto al sostener que la creación de la Liga salvadoreña se dio gracias al trabajo de Farabundo Martí. Así lo señala en el siguiente fragmento:

Parecido a lo que sucedería en Argentina, en este país la Liga se formó con base en dos secciones paralelas: la primera, fundada por Martí, tuvo un contenido mucho más proletario; la segunda, mayoritaria, fue creada más tarde por un grupo de intelectuales moderados provenientes de sectores medios y burgueses, cuyo trabajo se facilitaba porque su secretario, el periodista Miguel Pinto, era al mismo tiempo director del diario más importante de la capital ${ }^{85}$.

Efectivamente, existieron dos ligas antimperialistas en El Salvador; sin embargo, frente a la afirmación que Martí fundó la organización más cercana al proletariado, se debe señalar que al menos en el mes de diciembre de 1926, como se vio en el cuadro $N^{\circ} 3$, Farabundo Martí no figuraba dentro del secre- tariado del sector salvadoreño de la sección centroamericana de la Liga Anti-Imperialista de las Américas. En esa línea, Jorge Arias Gómez, biógrafo de Martí, apunta a que el líder comunista sí entró en contacto con la LADLA pero hasta el año 1928. Así lo expone Arias Gómez:

En cuanto a Martí, hay que destacar que en la primavera de 1928 viajó inesperadamente a Nueva York para tomar contacto con la dirección central de la Liga Antiimperialista de las Américas. Existen suficientes presunciones como para asegurar que fue en esta ocasión que la Liga Antiimperialista le encargó a Farabundo Martí que se situara en Nicaragua como representante suyo ante las huestes guerrilleras del general Sandino ${ }^{86}$. 
Evidentemente, la información que se tiene sobre la LADLA es limitadísima, razón por la cual no se puede comprobar si realmente es un desatino de su parte o si realmente Martí fue su fundador. Lo que sí es irrebatible es la necesidad de aclarar todo el desenvolvimiento de la LADLA en El Salvador. En ese sentido, abordar dicha organización en ese periodo nos lleva a otro tema de interés. Nos ofrece pistas sobre el incipiente movimiento comunista salvadoreño; es decir, a través de esta agrupación cominternista podemos aproximarnos a un tramo poco estudiado de la historia de la izquierda de El Salvador previo a la fundación del Partido Comunista Salvadoreño (PCS), ocurrida en 1930.

En conclusión, la suscripción del secretariado salvadoreño a los fines de la LADLA y a sus principios es incuestionable. Se debe recordar que Nicaragua tomó importancia para dicha organización continental hasta 1928. Por otra parte, como referencia adicional, es interesante comparar la estructura entre ambas organizaciones: la primera como una asociación compuesta por estructuras más identificadas con la democracia liberal, esto es, a través de un sistema presidencial; la segunda, como una estructura a la usanza comunista, es decir, constituida por secretariados.

\subsection{Expansión y actividades de la Liga Antiimperialista de San Salvador}

Ahora bien, retomando la caracterización de la liberal Liga Anti-Imperialista de San Salvador, conviene entonces citar sus principales labores, las cuales consistieron, principalmente: en la creación de organizaciones similares en otras ciudades importantes del país, organizar manifestaciones, elaborar textos para su publicación en periódicos nacionales e internacionales; finalmente, colaborar como formadores en las distintas Universidades Populares $^{87}$ del país. Sobre este último punto, el obrero comunista Miguel Mármol sostiene que uno de los principales intelectuales involucrados en la Universidad Popular de San Salvador fue el Dr. Salvador R. Merlos, segundo vocal de la Liga liberal. Así lo narra Mármol:

Las cátedras eran impartidas por muchos intelectuales y profesionales demócratas, como el Dr. Salvador Ricardo Merlos, y versaban sobre temas de la economía, el derecho y la ciencia de la política. Todos los profesores, felizmente, insistían mucho en situar el papel del enemigo principal que tenía para nuestros pueblos el imperialismo norteamericano y en sus rasgos más generales nos daban una idea de la estructura de la sociedad, desde el punto de vista de división clasista. La verdadera ideología del proletariado no aparecía, sin embar- 
go, más que fragmentariamente, matizada con los ingredientes de la ignorancia, del idealismo, de la falta de información histórica, e inclusive de la tergiversación mal intencionado que ya para entonces se daba en algunos casos concretos. Pero no por ello el entusiasmo era menor. Los alumnos de la Universidad Popular nos sentíamos como el que ve la luz que señala la salida del laberinto oscuro y angustioso ${ }^{88}$.

Es interesante la crítica que hace Mármol a las figuras que acompañaron el proceso formativo de la Universidad Popular; concretamente a los docentes liberales. Sin embargo, para efectos del presente artículo, el comentario del dirigente comunista reafirma el interés liberal de algunos docentes vinculados a la Liga de San Salvador, tal es el caso del Dr. Salvador Ricardo Merlos. Otro ejemplo de la participación de los miembros antimperialistas en la Universidad Popular acaeció en septiembre de 1927. El Dr. José de Jesús Zamora, primer vocal de la liga liberal, desarrolló una conferencia titulada "La intervención de los Estados Unidos en Centroamérica. Sus causas internas y externas". Según la reseña de la actividad, la disertación fue un éxito, la asistencia fue numerosa y Zamora fue estruendosamente aplaudido, a la vez que sirvió para discutir sobre las formas de eliminar el intervencionismo yanqui en Centroamérica ${ }^{89}$.
En definitiva, en ambos ejemplos, el contenido de las lecciones o conferencias desarrolladas en el seno de la Universidad Popular hacen referencia al problema del intervencionismo estadounidense, no a una temática relacionada a la lucha de clases, a pesar que el público estaba compuesto fundamentalmente por obreros.

Ahora bien, respecto a la primera actividad, la creación de otras ligas fue una de las acciones iniciales que realizaron los miembros de la Liga liberal de San Salvador. El 30 de noviembre de 1926, Diario Latino publicó una nota en la que señalaba el interés de periódicos del occidente y oriente del país por alentar las ideas que sustentaban la formación de la Liga; de ahí entonces que se haya acordado nombrar delegados en varios departamentos del país para formar asociaciones afines, es decir, ligas antimperialistas con un talante liberal. Dicha nómina de comisionados se muestra a continuación en el cuadro $\mathrm{N}^{\circ} 4$. 


\section{Cuadro 4}

Delegados para fundar ligas anti-imperialista en el interior del país

\begin{tabular}{l|l}
\multicolumn{1}{c|}{ Ciudad } & \multicolumn{1}{c}{ Delgados para fundar asociaciones afines } \\
\hline Santa Ana & Don Rosendo Díaz Galiano y don Alberto García \\
Ahuachapán & Don Víctor M. Lagos y bachiller J. Luis Silva \\
Sensuntepeque & Doctor Félix María Baires \\
San Vicente & Doctor Florencia A. Torres \\
San Miguel & Don César Augusto Osegueda y don Ignacio Salinas \\
Zacatecoluca & Doctor Rafael Díaz \\
La Unión & General Agustín Martínez \\
Santa Tecla & Don Manuel Barba Salinas \\
\hline
\end{tabular}

Fuente: Elaboración propia con base en: "Actividades de la Liga AntiImperialista", Diario Latino (10728), martes 30 de noviembre de 1926, p. 1.

De ahí entonces que empezaran articularse en varias ciudades del país otras ligas antimperialistas, de corte liberal, cuyo fin era la defensa de Latinoamérica. Sin duda, es cautivador el surgimiento espontaneo de todas estas organizaciones; en ese sentido, se debe recordar que los sucesos en Nicaragua ocurridos en noviembre de 1926 fueron un verdadero punto de quiebre en la concepción antimperialista salvadoreña. El ascenso de Adolfo Díaz y su pronto reconocimiento por Estados Unidos, generó una radicalización y una eclosión antimperialista en varios sectores centroamericanos, el sector intelectual salvadoreño entre ellos.

Ahora bien, bajo este marco y con base a las fuentes consultadas puede afirmarse que las primeras localidades en crear y fundar ligas antimperialistas fueron: Chalchua$\mathrm{pa}^{90}$, Santa Ana, San Miguel y Sonsonate $^{91}$. En el caso de Santa Ana, la Liga Anti-Imperialista se fundó el 9 de diciembre de 1926, y se adhirió a la Liga Anti-Imperialista de San Salvador. Su junta directiva quedó estructurada tal como aparece en el cuadro $\mathrm{N}^{\circ} 5$.

\section{Cuadro 5}

Liga Anti-Imperialista de Santa Ana

\begin{tabular}{l|l}
\multicolumn{1}{c|}{ Cargo } & \multicolumn{1}{c}{ Nombre } \\
\hline Presidente & Federico Vides \\
\hline Vicepresidente & Antonio Martínez Rubio \\
\hline Primer Vocal & Ángel Góchez Castro \\
\hline Tercer Vocal & Francisco Espinosa \\
\hline Segundo vocal & Carlos Menéndez Castro \\
\hline
\end{tabular}




\begin{tabular}{l|l}
\multicolumn{1}{c|}{ Cargo } & \multicolumn{1}{c}{ Nombre } \\
\hline Cuarto vocal & Alberto Castro A. \\
Quinto vocal & Tomás V. Pineda \\
\hline Tesorero & Santiago Díaz Palacios \\
\hline Secretario & Gilberto González \\
\hline
\end{tabular}

Fuente: Elaboración propia con base en: "Se ha fundado una Liga Anti-Imperialista en Santa Ana", Diario Latino (4506), martes 14 de diciembre de 1926, p. 1.

En la ciudad de San Miguel, la Liga Anti-Imperialista se fundó el domingo 19 de diciembre. Según la publicación que hace referencia a dicho acto, el Director del Diario de Oriente, César A. Osegueda, fue el encargado de dar el discurso de fundación. Según Diario Latino, éstas fueron parte de las palabras que Osegueda dictó:

Los que forman la Liga prometieron trabajar tesoneramente por la defensa de los principios de humanidad, amenazados por los Estados Unidos, y proclamados por los países latinoamericanos que tratan de sostener sus derechos de pueblos libres y de oponerse a la garra constrictora de los banqueros de Wall Street que tratan de exterminar la tradición y raza, con su asquerosa política del dólar ${ }^{92}$.

En resumen, la proliferación de organizaciones antimperialistas, constituidas como ligas, tuvo un gran auge entre diciembre de 1926 y febrero de 1927, probablemente dicho auge se debió, a nuestro parecer, por la efervescencia que despertó el despotismo y la arbi- trariedad estadounidense en Nicaragua. Finalmente, otras ciudades que crearon sus propias ligas figuran El Congo ${ }^{93}$, Ahuachapán ${ }^{94}$ y Santa Tecla ${ }^{95}$. Esta última se fundó en casa del doctor Miguel Coto Bonilla y su junta directiva se muestra en el cuadro $\mathrm{N}^{\circ} 6$.

\section{Cuadro 6}

\section{Directiva de la Liga Anti-Imperialista de Santa Tecla}

\begin{tabular}{l|l}
\multicolumn{1}{c|}{ Cargo } & \multicolumn{1}{c}{ Nombre } \\
\hline Presidente & Doctor Miguel Coto Bonilla \\
Vice-Presidente & Rubén Alonso Rochi \\
\hline Primer vocal & J. Antonio Dubón \\
Segundo vocal & Abraham F. Fuentes \\
Tercer vocal & Doctor Miguel Martínez \\
Cuarto vocal & Federico Martínez H. \\
\hline
\end{tabular}




\begin{tabular}{l|l}
\multicolumn{1}{c|}{ Cargo } & \multicolumn{1}{c}{ Nombre } \\
\hline Quinto vocal & Luis F. Mendoza \\
Sexto vocal & $\begin{array}{l}\text { Enrique Castillo M. } \\
\text { Rafael Viale } \\
\text { Tesorero }\end{array}$ \\
Secretarios & $\begin{array}{l}\text { Doctor José Manuel Mata y Manuel Barba S. } \\
\text { Comisión de propaganda } \\
\text { Francisco Núñez Arrué, Luis N. Lagos, Juan Cortés Funes, } \\
\text { Rafael Alberto Alvarado, Fidel López y Francisco Huezo. }\end{array}$ \\
\hline
\end{tabular}

Fuente: Elaboración propia con base en: "Como ha quedado organizada la Liga AntiImperialista en Santa Tecla", El Día (2236), viernes 4 de febrero de 1927, p. 1.

Por otra parte, entre las demás actividades importantes que desarrolló la Liga de San Salvador en su periodo fundacional, se encuentran la organización y coordinación de manifestaciones en contra del imperialismo estadounidense y otras banderas de lucha relacionadas a éstas, entre las cuales destacan la solidaridad con el Presidente de México, Plutarco Elías Calles y con el pueblo nicaragüense. Algunos ejemplos de estas actividades ocurrieron en el mes de enero de 1927. El 21 de enero, El Día publicó una nota que invitaba a las sociedades gremiales del país para que en- viaran un designado a la próxima sesión de la Liga Anti-Imperialista; el objetivo era la organización de una gran manifestación en contra de Estados Unidos ${ }^{96}$. De igual manera, en el departamento de Santa Ana se preparaba una manifestación con el mismo tinte político, que, a su vez, iba ser dedicada a México y a Nicaragua por ser los dos lugares donde la presión imperialista se manifestaba con mayor vehemencia. Por esa razón, estaban invitados el Ministro Mexicano en El Salvador, Ing. Julio A. Madero y un representante del presidente liberal Juan Bautista Sacasa. Así lo describe la nota:

Anoche organizóse una manifestación popular de cinco mil personas que recorrieron las calles. Oradores condenaron enérgicamente la política imperialista de Norte América con respecto a Nicaragua y México. Para el próximo domingo la Liga Anti Imperialista prepara otra, en que exhibirán banderas de todas las repúblicas hispanoamericanas, conducidas por ciudadanos respectivos de los países. Cada día aumenta el disgusto popular contra la política del dólar ${ }^{97}$.

El sábado 29 de enero La Prensa publicó una reseña acerca de las labores que realizaba la Liga centrándose en la organización de la gran manifestación que prepara- ba en contra del intervencionismo estadounidense. Según el periódico, Miguel Pinto, presidente de la Liga, expuso el objeto de la sesión y la razón para la que habían sido 
invitados los representantes de las diversas asociaciones capitalinas: "darle forma tangible a una manifestación popular que, tanto por el número, como por la imponencia, compostura y seriedad signifique el genuino sentir del pueblo salvadoreño, en el asunto de la hegemonía yanqui en América Latina" ${ }^{\prime \prime}$.
En síntesis, en dicha sesión se acordó celebrar la manifestación el domingo seis de febrero a las tres de la tarde. El punto de encuentro para la actividad fue el Campo de Marte. De igual manera, quedó resuelto que la directiva de la Liga concluyese la organización de la marcha. Por otra parte, es importante destacar las organizaciones invitadas que participaron en dicha sesión:

Asistieron los delgados siguientes: Don Santiago David García y Manuel de J. Mena, por la Regional de Trabajadores; Don Julio G. Teresón, por la Sociedad de Artesanos "La Concordia»; don Abel Ciudad Real, por la Sociedad de Obreros del Salvador Federada; Don Leónidas Ticas M. por la Sociedad de Empleados de Comercio; Don Alfonso Cañas, por la Sociedad Estudiantes de Jurisprudencia; Don Enrique Cañas, por el Consejo Obrero; Don Víctor Manuel Noublen, por la Sociedad de Estudiantes de Medicina ${ }^{99}$.

Como se puede observar en la anterior cita, la liga liberal logró articular diversos sectores sociales. El listado muestra una heterogénea participación, desde sectores obreros hasta sectores estudiantiles y capas medias. Sin duda, el éxito de esa aglutinación responde al rechazo de la política expansionista estadounidense; no obstante, no se puede menospreciar el liderazgo alcanzado por el movimiento antiimperialista liberal, ni su carácter nacionalista, pluralista e incluyente.

Finalmente, otra de las actividades importantes que desempeñó la Liga antimperialista capitalina fue la producción intelectual. Es decir, la redacción del pensamiento antimperialista latinoamericano. Si bien es cierto, varios de sus integrantes escribían constantemente en los periódicos, una actividad que tuvo mucho peso fue la propaganda de los ideales antimperialistas; para ello acordaron formular un cuestionario dirigido a pensadores internacionalistas de América Latina. El documento estuvo bajo la responsabilidad de Rosendo Argüello, José de Jesús Zamora, Constantino González y Juan Felipe Toruño. Dicho cuestionario se lanzó a todo el continente y tuvo las siguientes preguntas: 


\section{Cuestionario de la Liga Anti Imperialista para el Continente} Colombino

1. ¿Qué objeto tienen los Congresos Panamericanos en presencia de los continuos atentados del imperialismo norteamericano?

2. ¿Qué ventajas trae la sumisión que observan la mayoría de los Gobiernos latinoamericanos ante la pérdida diplomacia del dólar?

3. ¿¿Qué métodos prácticas deben sugerirse para asegurar la independencia de las pequeñas nacionalidades de la América Española?

4. ¿Será patriótico comprometer con empréstitos onerosos la independencia de los pueblos hispanoamericanos?

5. ¿Deben los Gobiernos continuar otorgando concesiones y privilegios a ciudadanos o empresas norteamericanas?

6. ¿Qué importancia tendría sistematizar el boicoteo a los productos estadunidenses, como medio de defensa y sanción contra el artero imperialismo norteamericano?

7. El reconocimiento de un Gobierno de Latino América por los Estados Unidos, ¿implica alianza, protección e intervención de parte del Gobierno reconocedor?

8. El reconocimiento de un Gobierno de Hispano América por parte de los Estados Unidos ¿obliga a los otros gobiernos a otorgar igual reconocimiento?

9. ¿Debe sustituirse el Panamericanismo por el Iberoamericanismo?

10. Caso de subsistir el Panamericanismo, ¿convendría que su cede permanezca en Washinton y que siga como Director, indefinidamente, un ciudadano de Estados Unidos?

11. En vista del desarrollo alcanzado política y económicamente por algunos de los países de la América española, 
¿no se impone la necesidad de adoptar una pauta de política internacional que nos ponga a salvo de la interpretación imperialista de la Doctrina Monroe?

12. Dada la notoria injusticia con que proceden los Estados Unidos como árbitros de las disputas territoriales, ¿sería conveniente continuar erigiéndolos en jueces de toda controversia?

13. En el caso particular de Centro América, y convencidos de la ineficacia y peligros que apareja la dolorosa injerencia de los Estados Unidos en la celebración de pactos centroamericanos, ¿será patriótico concederles participación en dichos tratados?100

Ciertamente, a lo largo del periodo que cubre esta investigación, no se refleja respuesta de dicho formulario; sin embargo, es oportuno dejar claro que se han consultado fuentes hasta el año de 1927.

En definitiva, como bien señala López Bernal: "aunque la mayoría de los dirigentes de la Liga Antiimperialista eran intelectuales, sus planteamientos rápidamente encontraron eco entre los obreros y los estudiantes ${ }^{\prime \prime 101}$. Efectivamente, su producción teórica, a través de periódicos o conferencias, llegó a los espacios donde se nutrió la población sobre las ideas antiimperialistas de la época; prueba de ello fueron todas las adhesiones y suscripciones de los distintos sectores de la población.

En resumen, en este último apartado se buscó mostrar la ideología y las principales ideas políticas de la Liga Anti-Imperialista de San
Salvador, a la vez, sus principales actividades y labores para lograr su causa. Ahora bien, todo el ideario antes comentado se enmarca dentro del periodo fundacional que comprende desde noviembre de 1926 hasta diciembre de 1927. Por otra parte, es importante señalar que a partir de septiembre de 1927 la información registrada en los periódicos disminuyó considerablemente. Si bien es cierto, las fuentes consultadas ofrecen mayor información en los primeros meses de funcionamiento, entiéndase noviembre de 1926 a marzo de 1927, a partir de abril no dejaron de aparecer notas relacionadas al funcionamiento de la Liga; no obstante, a partir de septiembre la información propiamente de la Liga no presentó mayor ocupación en las páginas de los rotativos: al parecer, la situación en Nicaragua y el discurso antiimperialista expresado en artículos de opinión dominaron los impresos. 


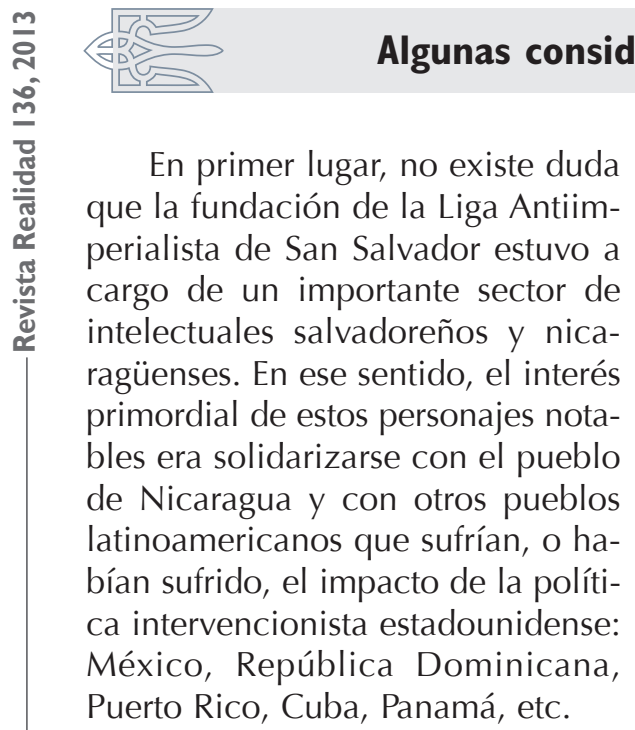

Asimismo, puede afirmarse que otra de las preocupaciones que movieron a estos hombres vinculados a las letras era acercar las ideas ilustradas que ya empezaban a marcar la vida política de otras sociedades latinoamericanas, como por ejemplo el caso de México. En otras palabras, buscaban establecer un orden democrático, autónomo que, a su vez, permitiera completa independencia en términos económicos. De ahí entonces su postura nacionalista que, a nuestro parecer, no se trataba de un nacionalismo chovinista, sino un enorme deseo por desarrollar todos los aspectos (políticos, económicos, sociales y culturales) que limitaban a El Salvador y a la región.

En segundo lugar, es importante destacar que, a partir del análisis elaborado en el presente artículo, la Liga de San Salvador no se fundó para legitimar a otra potencia que compitiera contra Estados Unidos u otras potencias europeas, entiéndase la Unión Soviética. Ni para legitimar partidos políticos de ninguna corriente ideológica. La Liga se erigió con el interés de contrarrestar al que para ellos era el principal enemigo de las naciones: Estados Unidos. No obstante, no consideraban enemigo a todo el país, sino a un pequeño sector, el sector empresarial: Wall Street, es decir, el grupo financiero y poderoso que dictaba la política exterior norteamericana.

En definitiva, la Liga Antiimperialista constituida en la capital salvadoreña no tenía filiación marxista-leninista. Con base a las fuentes consultadas, puede afirmarse que ideológicamente no logró identificarse y suscribirse al discurso e ideario cominternista que caracterizó a la mayoría de ligas fundadas en el continente. De hecho su postura estaba más cercana a movimientos políticos como la Revolución agraria mexicana e incluso a algunos postulados del APRA. En otras palabras, puede afirmarse que la Liga de San Salvador desde su actitud nacionalista y liberal, adoptó un discurso que combinó al menos dos corrientes antiimperialistas: la unionista (con tinte arielista) y la nacionalista revolucionaria. Ahora bien, a pesar de no acercarse ideo- 
lógicamente con la LADLA y menos a Moscú (al menos en su periodo fundacional), tampoco rechazaron al movimiento obrero, ni comunista; lejos de eso se vincularon a éstos con el fin de lograr su propósito: enfrentar al poderío estadounidense.

Finalmente, se debe apuntar que conviene hacer una revisión de nuevas fuentes, adicionales a las que se estudiaron en esta investigación, para analizar la sección cen-

\section{Notas}

1 "Nicaragua", El Libertador (12), Vol. II, 1 de junio de 1927, p. 5. Disponible en: http://ru.ffyl.unam.mx:8080/ jspui/handle/10391/914. El Libertador, órgano de la Liga Antiimperialista de las Américas (LADLA) fue una revista editada en la Ciudad de México entre 1925 y 1929. Los directores de la revista fueron: Úrsulo Galván, Enrique Flores, Salvador de la Plaza, Diego Rivera y German List Arzubide. Entre sus principales colaboradores destaca Julio Antonio Mella. Disponible en: http://ru.ffyl.unam.mx:8080/jspui/ bitstream/10391/914/2/el_libertador_cuadernillo.pdf

2 Xiomara Avendaño Rojas, "Al lado o enfrente del Imperio. La diplomacia de Nicaragua, México y El Salvador ante el Tratado Bryan-Chamorro", Revista Estudios Centroamericanos, Vol. 63 (713714), 2008, p. 154.

3 Ibíd.

4 Jussi Pakkasvirta, ¿Un continente, una nación? Intelectuales latinoamericanos, comunidad politica y las revistas culturales en Costra Rica y en el Perú (1919-1930), Academia Scientiarum Fennica, Finlandia, 1997, pp. 83-84. troamericana de la LADLA y para revisar la orientación que tomó la Liga liberal de San Salvador en los años próximos a la crisis económica mundial y frente a la hegemonía comunista de Stalin. En la misma línea, corresponde reconstruir el movimiento cominternista antiimperialista y estudiar si existió alguna vinculación más fuerte entre las dos corrientes documentadas en el caso salvadoreño o si ocurrió lo contrario.

5 Carlos Beorlegui, Historia del pensamiento filosófico latinoamericano: una búsqueda incesante de la identidad, Universidad de Deusto, $3^{\text {a }}$ edición, 2010, p. 373.

6 Véase: Teresa García Giráldez, La dicotomía imperialismo-antimperialismo en las redes intelectuales unionistas centroamericanas (1890-1930), en Marta Elenas Casaús Arzú, El lenguaje de los ismos: Algunos conceptos de la modernidad en América Latina, F\&G Editores, Guatemala, 2010, p. 274.

7 Véase: Rodolfo Cerdas Cruz, La hoy y el machete: La Internacional Comunista, América Latina y la revolución en Centroamérica, EUNED, San José, Costa Rica, 1986, p. 91.

8 En 1929 Sandino realizó un viaje a México para solicitar ayuda política y armamentística al presidente Portes Gil. Lo acompañaron en su viaje su Estado Mayor constituido por Farabundo Martí (salvadoreño), Rubén Ardila Gómez (colombiano) y Gregorio Gilbert (dominicano), entre otros. En ese marco, el Partido Comunista Mexicano (PCM) le exigió, a través de Farabundo Martí, que tomara posición respecto a la lucha que libraba en Nicaragua, si era "lucha 
nacional o lucha de clases"; a la vez, fue duramente cuestionado por recibir ayuda del gobierno mexicano. Ante la firme postura del caudillo nicaragüense, el PCM rompió relaciones con él e incluso lo acusó de corrupción. Véase: Volker Wünderich, Sandino, una biografía política, op. cit., pp. 247-252.

En esa misma sintonía, el órgano divulgativo del Partido Comunista de México (PCM), El Machete, en junio de 1930 publicó una noticia en la que acusaba al guerrillero nicaragüense de haber traicionado "a las masas obreras y campesinas de su país y del continente y al movimiento antiimperialista y revolucionario mundial". Véase: "La traición de Augusto C. Sandino", El Machete (181), 9 de junio de 1930, p. 17.

9 Rodolfo Cerdas Cruz, op. cit., p. 112.

10 Ibíd., p. 114.

11 El Libertador fue el órgano y vocero de la Liga Antiimperialista de las Américas (LADLA). Según Ricardo Melgar Bao, El Libertador abrió sus espacios a colaboradores que no eran militantes cominternistas, aunque sí figuras intelectuales del amplio espectro antimperialista. Véase: Ricardo Melgar Bao, "El universo simbólico de una Revista Cominternista: Diego Rivera y El Libertador", Revista Convergencia, Instituto Nacional de Antropología e Historia-Morelos, enero-abril del 2000 (21), pp. 122-123.

12 Ibíd., p. 123.

13 Mario Oliva Medina, Dos peruanos en Repertorio Americano: Mariátegui y Haya, Instituto de Estudios Latinoamericanos, Heredia, 2004, p. 18.

14 Carlos Beorlegui, op. cit., p. 459.

15 José Carlos Mariátegui, Obra política, Ediciones Era, México D.F., 1979, p. 275.
16 Ibíd., p. 278.

17 Francisco Zapata, Ideología y política en América Latina, Colegio de México, México D.F., 1990, p. 17.

18 Ibíd., p. 129.

19 Es interesante destacar cómo finaliza la reseña o recensión mencionada. A continuación transcribo un breve fragmento: "Y así, toda la obra está llena de bellezas y verdades contundentes que denuncian el espíritu investigador del psicólogo y del crítico candente, que no teme decir la verdad, porque él es como un apóstol que va por donde quiera con la guerra para infundir la paz". Véase: "Notas bibliográficas", Revista del Ateneo de El Salvador (107-108), abril y mayo de 1926, p. 4194.

20 En ese marco, José Vasconcelos corrió como candidato a la primera magistratura. La lectura que hizo el sector estudiantil salvadoreño sobre ese hecho fue publicado en el semanario Opinión Estudiantil. No cabe duda de que los estudiantes veían con entusiasmo y admiración el proceso mexicano. Véase: "Las próximas elecciones: Vasconcelos y Gómez Zárate", Opinión Estudiantil (17), $\sigma^{a}$ época, sábado 20 de julio de 1929, p. 1.

21 Jussi Pakkasvirta, Victor Raúl Haya de la Torre en Centroamérica ¿L a primera y última fase del aprismo internacional, Ponencia presentada en el V Congreso Centroamericano de Historia, San Salvador, 2000, p. 4.

Disponible en: http://hcentroamerica. fcs.ucr.ac.cr/Contenidos/hca/cong/ mesas/cong5/docs/PPo18.pdf

22 Véase: "Víctor Raúl Haya de la Torre" en Mario Oliva Medina, op. cit., p. 55.

23 La Asociación General de Estudiantes Universitarios Salvadoreños (AGEUS), 
se trató de una asociación política- estudiantil fundada en 1927 y legalizada en 1931. Según Ricardo Argueta, la AGEUS actuaba al interior de los muros universitarios en defensa de los intereses estudiantiles; sin embargo, también buscaba democratizar el país y exigir, a las elites, mayor interés en la cuestión social. Véase: Ricardo Argueta, "La Asociación General de Estudiantes Universitarios Salvadoreños (AGEUS) a través de la prensa escrita (1927-1961)", Tesis para optar al grado de Magíster Scientiae, Posgrado en Historia de la Universidad de Costa Rica, 2006, p. 231.

24 Ricardo Argueta, “¿Quién manda en casa? Influencia norteamericana, antimperialismo y martinato en El Salvador (1911-1944)", Revista Estudios Centroamericanos, Vol. 63 (713-714), UCA editores, marzo-abril 2008, San Salvador, p. 172.

25 Alfonso Rochac, en el año de 1926 ocupó la secretaría de estudiantes e intelectuales de vanguardia del sector salvadoreño de la sección centroamericana de la Liga Antiimperialista de las Américas (LADLA), organización vinculada a la internacional comunista.

26 "Mensaje de Haya de la Torre a la juventud estudiantil y obrera de El Salvador", Opinión Estudiantil (1), 6 a época, sábado 23 de marzo de 1929, p. 1.

27 Ibíd.

28 La discusión sobre el aprista puede encontrarse en las siguientes fuentes: "Campaña contra El Salvador", El Día (2732), miércoles 17 de octubre de 1928, p.1.; "Comentarios: xenofobia y narcicismo tico", El Día (2733), jueves 18 de octubre de 1928, p.1; "Comentarios: la filosofía del silencio", El Día (2736), lunes 22 de octubre de 1928, p.1.
29 Víctor Raúl Haya de la Torre en Mario Oliva Medina, Dos peruanos en Repertorio Americano: Mariátegui y Haya, op. cit., p. 49.

30 Ibíd., p. 52.

31 Teresa García Giráldez, op. cit., p. 269.

32 Ibíd.

33 Froylán Turcios (1875-1943), escritor y periodista hondureño. Dirigente del movimiento antiimperialista centroamericano. Apoyó la gesta del patriota nicaragüense, Augusto Sandino. Llegó a ser su representante en el extranjero. Desde sus publicaciones realizó una férrea labor de defensa nacional denunciando la política intervencionista implementada por Estados Unidos en la región centroamericana y caribeña. Véase: Sergio Ramírez, El pensamiento vivo de Sandino, op. cit., pp. 99-103. Una breve referencia biográfica de Turcios se encuentra en el Sistema Bibliotecario de la Universidad Nacional Autónoma de Honduras (UNAH). Disponible en: https://www.unah.edu.hn/?cat=2877.

34 Teresa García Giráldez, op. cit., p. 273.

35 Ibíd., p. 281.

36 Ibíd., p. 279.

37 "Manifiesto del Núcleo Nacionalista La Joven Centro América', Diario Latino (10936), sábado 13 de agosto de 1927, pp. 1-2.

38 "Manifiesto del grupo nacionalista La Joven Centro América”, El Día (2384), lunes 15 de agosto de 1927, p. 1.

39 Ibíd., pp. 4-5.

40 Alberto Masferrer, "Cuatro de Julio", Patria. Artículos recopilados por Pedro Geoffroy Rivas, Editorial Universitaria, San Salvador, 1960, p. 45.

41 Daniel Kersffeld, "La Liga Antiimperialista de Costa Rica: Una escuela de 
cuadros para el partido comunista de Costa Rica", Revista Estudios, Universidad de Costa Rica, (22), 2009, p. 106.

42 Ibíd., p. 106.

43 Víctor Raúl Haya de la Torre, El Antiimperialismo y el APRA, Fondo Editorial del Congreso del Perú, Lima, 2010, p. 98. El Antiimperialismo y el APRA fue publicado originalmente en idioma inglés bajo el título: "¿Qué es el A.P.R.A.?" en la revista londinense The Labour Monthly: A Magazine of International Labour (12), vol. 8, diciembre de 1926, pp. 756-759. En 1936, fue publicado en castellano una versión aumentada ya bajo el título: El Antiimperialismo y el APRA. Véase: Víctor Raúl Haya de la Torre, El Antiimperialismo y el APRA, $2^{\mathrm{a}}$ edición, Ediciones Ercilla, Santiago de Chile, 1936.

44 Daniel Kersffeld, Contra el Imperio: Historia de la Liga Antimperialista de las Américas, Siglo XXI, México D.F., 2012, p. 104.

45 Víctor Raúl Haya de la Torre viajó en el año de 1924 a Europa y llegó a la Rusia Soviética; posteriormente entabló correspondencia con el Secretario de Asuntos Latinoamericanos del Comintern, Alfred Stirner. Véase: Jussi Pakkasvirta, ¿Un continente, una nación? Intelectuales latinoamericanos, comunidad politica y las revistas culturales en Costra Rica y en el Perú (1919-1930), op. cit., p. 94.

46 Ibíd., p. 93.

47 Daniel Kersffeld, Contra el Imperio: Historia de la Liga Antimperialista de las Américas, op. cit., p. 105.

48 Ibíd., p. 109.

49 Daniel Kersffeld, Contra el Imperio: Historia de la Liga Antimperialista de las Américas, op. cit., p. 95.

50 Ibíd., p. 95. La delegación latinoamericana que asistió a Bruselas apareció publicada en El Liberador. Véase: "Las Resoluciones sobre la América Latina”, El Libertador (12), Vol II, 1 de junio de 1927, p. 5.

51 Ibíd., p. 97.

52 Para La Chispa, órgano del Partido Comunista de Argentina, los objetivos del Congreso de Bruselas eran: La organización del movimiento internacional contra la opresión en las colonias y el imperialismo mundial, la coordinación de fuerzas para prestar apoyo moral y material a los pueblos y a las organizaciones en lucha contra el imperialismo, el establecimiento de relaciones permanentes entre todos los movimientos de liberación de las colonias y semicolonias con el movimiento obrero y revolucionarios de las metrópolis. Véase: Ibíd., p. 96.

53 Para la dirección de la LADLA, en el Congreso de Bruselas se establecerían relaciones permanentes entre todas las fuerzas que luchaban contra el imperialismo. Según Daniel Kersffeld, así lo indicó la LADLA en El Libertador: "Las fuerzas antimperialistas del continente podrían llegar a un acuerdo sobre la lucha antimperialista continental y unirían el movimiento de este continente al movimiento internacional de los pueblos coloniales amenazados por el imperialismo y las grandes potencias". Véase: Ibíd., p. 96.

54 "Se recomienda para esta sesión una puntual asistencia, pues se tratará de acreditar al Delegado que representará dicha asociación en el Congreso Anti-Imperialista que se reunirá próximamente en un país europeo". Véase: "Sesión de la Liga Anti-Imperialista, Diario Latino (10747), miércoles 22 de diciembre de 1926, p. 1.

55 "Cable inalámbrico de Méjico", El Día (2243), lunes 21 de febrero de 1927, p. 3. 
56 Daniel Kersffeld, Contra el Imperio: Historia de la Liga Antimperialista de las Américas, op. cit., p. 98.

57 Ibíd., p. 99.

58 Ibíd., p. 103.

59 Ibíd., p. 126.

60 Ibíd., p. 127.

61 "La Alianza Continental ha sido fundada en Buenos Aires, R. A.", Diario Latino (10947), viernes 26 de agosto de 1927, p. 1.

62 Ibíd., p. 6.

63 "Alianza Continental", Diario Latino (10948), sábado 27 de agosto de 1927, p. 1.

64 Ibíd., p. 1.

65 Ibíd., p. 4

66 "Alianza Continental”, Diario Latino (10949), lunes 29 de agosto de 1927, p. 2.

67 Daniel Kersffeld, Contra el Imperio: Historia de la Liga Antimperialista de las Américas, op. cit., pp. 133-134.

68 La Federación Regional de Trabajadores de El Salvador (FRTS), era una organización obrera creada en 1924. Su interés primordial era la dirección y consolidación del sindicalismo salvadoreño. En palabras de Miguel Mármol, la FRTS fue "el gran instrumento con que la clase obrera comenzaría a darse su lugar en la historia salvadoreña". Véase: Roque Dalton, Miguel Mármol: los sucesos de 1932 en El Salvador, Ocean Sur, Colombia, 2007, p. 71.

69 Véase: Carlos Gregorio López Bernal, Tradiciones inventadas y discursos nacionalistas: el imaginario nacional de la época liberal en El Salvador, 1876-1932, Editorial Universitaria, San Salvador, 2007, p. 193.

70 "Se funda una Liga Anti-Imperialista en esta capital", Diario Latino (10720), martes 23 de noviembre de 1926, p. 1 .

71 "Se ha organizado una Liga AntiImperialista", La Prensa (4506), martes 23 de noviembre de 1926, p. 1.

72 De hecho diez meses más tarde de constituida la Liga de San Salvador, se fundó en la misma capital una organización denominada "Asociación autonomista nicaragüense", cuyo objetivo era defender moralmente la soberanía de Nicaragua. Entre sus fundadores figuraban cinco miembros de la Liga Antiimperialista de San Salvador. Véase: "Se ha fundado en esta capital la asociación nicaragüense", Diario Latino (10958), jueves 8 de septiembre de 1927, p. 1.

73 "Se funda una Liga Anti-Imperialista en esta capital", Diario Latino (10720), op. cit., p. 1.

74 "La sesión de anoche de la Liga AntiImperialista", Diario Latino (10723), miércoles 24 de noviembre de 1926, p. 1. En otro tema, las adhesiones a la Liga Anti-imperialista siguieron publicándose, al menos, hasta terminar el año. Véase: "Más adhesiones a la Liga Anti-imperialista, Diario Latino (10733), lunes 6 de diciembre de 1926, p. 1.

75 "Manifiesto de la Liga Anti-Imperialista a los pueblos iberoamericanos", La Prensa (4512), martes 30 de noviembre de 1926, p. 1.

76 "Manifiesto de la Liga Anti-Imperialista de San Salvador a los pueblos iberoamericanos", Diario Latino (10727), sábado 27 de noviembre de 1926.

77 "Manifiesto de la Liga Anti-Imperialista a los pueblos iberoamericanos", El Día (2180), lunes 29 de noviembre de 1926, p. 1.

78 Ibíd.

79 Ibíd., p. 5. 
80 Ibíd.

81 "Bases de la Liga Anti-Imperialista de las Américas", Diario Latino (10754), jueves 31 de diciembre de 1926, p. 2. Mayúsculas en el original.

82 Ibíd.

83 Ibíd.

84 Ibíd.

85 Daniel Kersffeld, Contra el Imperio: Historia de la Liga Antimperialista de las Américas, op. cit., p. 90.

86 Jorge Arias Gómez, Farabundo Martí: la biografía clásica, Ocean Sur, México D. F., 2010, p. 46.

87 Las Universidades Populares fueron espacios educativos no formales creados para proporcionar instrucción política y cultural a obreros y campesinos. En el caso de San Salvador, fue fundada por la Federación Regional de Trabajadores de El Salvador (FRTS). Véase: Ricardo Argueta, “¿Quién manda en casa? Influencia norteamericana, antiimperialismo y martinato en El Salvador (1911-1944)", op. cit., p. 172. Ahora bien, la importancia de dichas academias populares para el antiimperialismo latinoamericano no sólo fue en El Salvador, sino para todo el continente. Uno de los ejemplos más exitosos fue el de la Universidad Popular "José Martí" (UPJM) en Cuba. Véase: Daniel Kersffeld, De cara al sol, Editorial Historia, La Habana, 2009, pp. 11-12.

88 Roque Dalton, op. cit., p. 81.

89 "La conferencia del Dr. José de Jesús Zamora en la Universidad Popular", Diario Latino (10958), jueves 8 de septiembre de 1927, p. 1.

90 "En Chalchuapa quedó definitivamente organizada la Liga Anti-imperialista" Diario Latino (10740), martes 14 de diciembre de 1926, p. 1.
91 "En Sonsonate, se comunicó la fundación de una Liga similar, la cual tiene por Directiva provisional la siguiente: Presidente: doctor Pedro Ordóñez Díaz; Vicepresidente, doctor Joaquín Mesa Sandoval; Primer Vocal, don José Anselmo Peñalba; Segundo, Vocal, doctor Felipe Navarro, y Secretario, don José María Sifontes". El acta fue transcrita y firmada por más de cincuentas personas. Véase: "Sesión de la Liga Anti-Imperialista", Diario Latino (10739), lunes 13 de diciembre de 1926, p. 1.

92 "Se fundó la Liga Anti-Imperialista en San Miguel", Diario Latino (10747), miércoles 22 de diciembre de 1926, p. 1.

93 "Otra Liga Anti-Imperialista", La Prensa (4561), jueves 27 de enero de 1927, p. 12.

94 "Comunicación de la Liga Anti-Imperialista de Ahuachapán", El Día (2235), Jueves 3 de febrero de 1927 p. 1.

95 "Como ha quedado organizada la Liga Anti-Imperialista en Santa Tecla", El Día (2236), viernes 4 de febrero de 1927, p. 1.

96 "La Liga Anti-Imperialista de esta capital está preparando una manifestación", El Día (2224), viernes 21 de enero de 1927, p.1.

97 "Manifestaciones de la Liga Anti-Imperialista en Santa Ana", El Día (2225), sábado 22 de enero de 1927, p. 1.

98 "Labores de la Liga Anti-Imperialista", La Prensa (4563), sábado 29 de enero de 1927, p. 15.

99 Ibíd.

100 "Sesión de la Liga Anti-Imperialista", Diario Latino (10867), viernes 20 de mayo de 1927, p. 1.

101 Carlos Gregorio López Bernal, op. cit., p. 195. 